\title{
Social networks and the diffusion of fertility control
}

Mark R. Montgomery

Population Council

John B. Casterline

Population Council

Follow this and additional works at: https://knowledgecommons.popcouncil.org/departments_sbsr-pgy

Part of the Demography, Population, and Ecology Commons, Family, Life Course, and Society Commons, and the International Public Health Commons How does access to this work benefit you? Let us know!

\section{Recommended Citation}

Montgomery, Mark R. and John B. Casterline. 1998. "Social networks and the diffusion of fertility control," Policy Research Division Working Paper no. 119. New York: Population Council. 


\section{Social Networks and the D iffusion of Fertility Control}

Mark R. Montgomery

John B. Casterline

1998 No. 119 


\title{
Social Networks and the Diffusion of Fertility Control
}

\author{
Mark R. Montgomery \\ John B. Casterline
}

Mark R. Montgomery is Senior Associate, Policy Research Division, Population Council, and Associate Professor of Economics, State University of New York at Stony Brook. His e-mail address is mmontgomery@popcouncil.org. John B. Casterline is Senior Associate, Policy Research Division, Population Council. His e-mail address is jcasterline@ popcouncil.org. The research reported here was supported by the Rockefeller Foundation and National Institutes of Health grant R01 HD34524-01A1. 


\begin{abstract}
Theories of the fertility transition now routinely reserve a place for diffusion effects. Two fundamental behavioral mechanisms account for such effects: social learning and social influence. Social learning refers to the acquisition of information from others. The information might have to do with a new technology or with the health, social, and economic consequences of decisions. In the case of fertility, individuals might learn from others about the availability of a new contraceptive, or about health side effects of certain contraceptives, or about the apparent gains and losses from having fewer children and investing in their schooling. Social influence refers to the power that individuals exercise over each other through authority, deference, and social conformity pressures. Our aim in this paper is threefold: to assemble the disparate concepts of the diffusion perspective into a coherent whole; to review the literature in and outside demography in the light of these concepts; and to present simulations and new data on the role of social networks, through which social learning takes place and social influence is exercised. Throughout the paper, we illustrate the issues with applications to Ghana, one of the sites being explored in new longitudinal research.
\end{abstract}

This material may not be reproduced in any form without written permission from the authors. 
Theories of the fertility transition now routinely reserve a place for diffusion effects (Mason 1997). Such effects arise because individuals are themselves members of larger groups. The information that is held by group members, the choices they make, and the outcomes that flow from them can all exert a powerful influence on individual incentives to innovate. In settings in which fertility has been high, such innovation may take the form of modern contraceptive adoption and fertility limitation. Under certain conditions, the individual-to-group connections establish pathways along which such innovative demographic behavior can diffuse.

What empirical evidence supports the view that diffusion matters to fertility decline? As we will show, proponents can find in the fertility literature numerous hints and indirect suggestions of a role for diffusion. Until very recently, however, the available data were insufficient to withstand rigorous scientific scrutiny. In the past three years, several groups of researchers have become engaged in long-term investigations that may better illuminate the contribution of diffusion. ${ }^{1}$ With the study of diffusion effects about to enter a new phase, this is an appropriate moment to take stock of what has been learned and to describe the new research directions that lie ahead.

\section{OVERVIEW}

Our aim in this paper is threefold: to assemble the disparate concepts of the diffusion perspective into a coherent whole; to review the literature in and outside demography in the light of these concepts; and to present simulations and new data on the role of social networks, which we take to be one of the key mechanisms in diffusion processes. Throughout the paper, we illustrate the issues with applications to Ghana, one of the sites being explored in new longitudinal research. The effort to understand the specifics of the Ghanaian case requires that concepts and illustrations be drawn from the broader literature in social science and fertility change. 
In our view, diffusion modeling can be regarded as a special case of multilevel modeling. It is distinctive in two respects: first, consideration of diffusion emphasizes a particular set of individual-to-group connections, those associated with information exchange and innovation; and second, it focuses attention on dynamic implications. If they are appropriately structured, the channels by which individuals are connected to groups can permit and even facilitate wholesale behavioral change - the dynamics can take the form of "cascade," "contagion," and "tipping point" phenomena. That diffusion effects have the potential to accelerate social change is well recognized; but it is less well understood that depending on social setting, they may also stifle innovation and bind individuals more tightly to the status quo.

In other work (Montgomery and Casterline 1996), we have argued that diffusion is best analyzed in terms of its two defining features: social learning and social influence. The concept of social learning is pertinent to environments that are characterized by flux and uncertainty, in which new choice options are coming to the fore but with associated costs and benefits that are not yet well understood. In such transitional settings, one individual may seek to understand the consequences of a new private decision, and may probe in various directions hoping to clarify the nature of its potential benefits and costs. The decision in question could be entirely novel, as in the case of adoption of a new technology, or socially novel in the sense that, among that person's peers, such decisions had previously been uncommon. Information about choices may be drawn from the individual's reference groups, the set of other persons with whom information is exchanged or who provide models illustrating the links between choice and outcome. We will describe the various reference groups and linkages as "social networks." Social learning thus encompasses both the social aspects of information acquisition and the filtering or distillation of that information into terms that are meaningful to individual choice. 
Social influence is a rather different concept. It refers to the collective power of institutions, structures of authority, and social groups to establish the larger context within which individuals must evaluate their private decisions. As individuals learn about the nature of the new choices, they may find that various groups, institutions, or local elites are positioned either to facilitate those choices or to constrain them. But such social structures are themselves rarely immutable or impervious to influence, and their nature may well change with the prevalence of innovation. For instance, social norms favoring high fertility may dissolve or be reconfigured as modern contraceptive use spreads.

\section{Contraceptive adoption}

The adoption of modern contraception may be strongly influenced by diffusion effects. One aspect of social learning has to do with the properties of contraceptive methods themselves - their levels of efficacy, where they may be obtained, the associated monetary and social costs, and the potential side effects of use. These are doubtless central concerns in settings where few people use contraception. Even in high-prevalence settings, however, the distribution of contraceptive knowledge will be uneven, and in certain groups, at least, social learning can continue to play an important role. The life-cycle aspect of learning also warrants study. Whatever the prevalence of contraception among adults, adolescents will have much left to learn about the nature and consequences of method use. They will often refer to the behavior of peers and others for guidance; and adolescents may find themselves constrained by peer group norms or by the institutionalized service delivery practices of family planning programs.

The scope for social learning is much broader than this focus on methods and means would suggest. In developing countries, where many society-wide transformations are underway, individuals may need to rely on social learning in order to extract the meaning for themselves of these larger forces. For example, 
social learning may be much involved in individual perceptions of mortality decline (Montgomery 1998) and in the effort to understand the risks and benefits of heavy investments in children's education. Learning in these dimensions involves issues distinct from the properties of contraceptive methods, but such learning could ultimately be expressed through contraceptive use.

Thus, there is merit in thinking broadly about the roles of diffusion and social influence. By no means does the adoption of a diffusionist perspective require one to abandon concern for socioeconomic determinants. Rather, the diffusion perspective helps to enrich understanding of the full force of these determinants. It draws attention to their role in forming the local social structure; and it introduces a distinction between their direct impacts and their spillover or social multiplier effects.

\section{Social multipliers and programs}

When seen from the viewpoint of reproductive health programs, the recognition of diffusion effects opens a new window on program evaluation. The essence of a diffusion dynamic is that the information or behavior of one person-let us say, a contraceptive adopter-can have spillover effects on the motivations of another-say, a potential adopter. This spillover effect, or informational externality, can be either positive or negative in character. That is, when considered by the potential adopter, the experience of an earlier user can help to tip the balance toward contraceptive use or can serve to dissuade the potential adopter.

Consider a case in which a family planning program reaches one person directly with services and information. If this person uses contraception, the program can rightly claim a portion of the credit. The diffusion perspective suggests that second-round, social multiplier effects also need consideration. When the example of the first contraceptive user persuades another person to adopt, the 
program might legitimately claim some measure of credit for the second adoption as well. Although it would be difficult to properly apportion this credit, the basic principle is that program effects extend beyond those individuals who are directly influenced by the program.

Once this principle is accepted, it implies the need to reconsider not only the social dimension of program effects, but also the geographic dimension. When different geographic areas are linked by social network ties, program efforts directed at one area can exert a spillover influence on contraceptive use in another. By emphasizing pathways such as these, the consideration of diffusion dynamics forces a rethinking of the conventional evaluation framework.

This much has long been known. Indeed, one of the earliest experimental interventions in family planning - the Taichung experiment, reviewed belowunderscored the significance of social multiplier and geographic spillover effects in contraceptive knowledge and adoption. The difficulty has been to properly estimate the size of these effects, and thereby understand the practical implications for evaluation. This task requires both rich longitudinal data and an appropriate conceptual and statistical apparatus. One longitudinal analysis (Montgomery and Casterline 1993) has found that in the case of Taiwan, estimates of family planning program effectiveness were greatly modified by consideration of diffusion dynamics. A conventional analysis of program impact, which ignored diffusion, suggested that no more than 5 to 20 percent of marital fertility decline could be attributed to program efforts. When the social multiplier effects of diffusion were taken into account, however, the estimates of program impact rose to over 30 percent.

Does the diffusion perspective also provide clear lessons for program design? The 1993 National Academy of Sciences report, Factors Affecting Contraceptive Use in sub-Saharan Africa, linked social networks to the prospects for increases in contraception, 
The challenge for policy ... is how to seize on the themes and motivations brought out by economic stagnation and crisis in a cost-efficient way, recognizing that initially the appeal of family limitation will not be in evidence across the full socioeconomic spectrum, and even the appeal of birth spacing via modern contraception may be resisted in some traditional quarters. One proposal, advanced by Lesthaeghe, is to exploit the concept of diffusion and the potential presented by sub-Saharan forms of local social organization.

It is clear that the provision of information and the social legitimation of modern contraception will be crucial to the prospects for service delivery. Given the budgetary constraints and limitations of personnel with which sub-Saharan governments must cope, national delivery strategies must tap a variety of local social networks. . . (National Academy of Sciences 1993:122-123)

The report went on to discuss the possible roles of local women's groups, marketing associations, local political associations, mutual aid and rotating credit groups, and traditional birth attendants, as well as various church and youth associations. This theme was echoed in Bongaarts and Bruce (1995), who asked how local African social structures and traditional community institutions might become involved in efforts to reduce "unmet need" for birth spacing. They envisioned a role for such institutions in the organization of service delivery and in the diffusion of information.

Although the potential exists, it is too soon to say whether the diffusion perspective will have a major impact on program design. In the Navrongo experiment, a large-scale family planning intervention set in northern Ghana (Nazzar et al. 1995), local social, religious, and political institutions have been enlisted in 
support of an innovative program of doorstep delivery of modern contraception. A longitudinal evaluation of diffusion dynamics is also underway.

With the preceding overview serving as background, we have organized the next sections of the paper as follows. We first provide a more formal definition of the concepts of social learning and social influence, the two fundamental components of diffusion theory. We then review the demographic and related social science literature on diffusion modeling; present results from an analytical simulation model of diffusion, with emphasis on the contribution of social networks; and provide empirical data from Ghana on social networks and contraceptive use in that context. In closing, we set out our conclusions.

\section{KEY CONCEPTS}

In developing countries, most adults are keenly aware of the flux and new uncertainties of their social environments. Mortality decline is underway, although its extent may be only dimly perceived; the prospects for wresting a living from agriculture may be threatened or undergoing radical change; new forms of human capital investments in children must be considered; and the perceived costs of children are often shifting in ways that might motivate lower fertility. In addition to this, most adults understand that new technologies are available for the control of fertility, with the new methods often being promoted by information and education campaigns and provided through government and private health services. Yet, each new decision option presents social and economic risks as well as potential benefits. In consequence, individuals will make use of information drawn from many sources to help resolve the uncertainties facing them and to clarify the benefits and costs associated with their private decisions.

In such environments, social learning may be described as follows. Consider an individual $i$ at time $t$. In weighing alternatives and making decisions, this 
person refers to an information set $I_{i, t}$, which summarizes his or her knowledge of all factors that might bear on decisions. Some aspects of the decision environment are not known with certainty, and these must be represented in terms of subjective expectations and measures of uncertainty. Such knowledge may have been created by the mingling of different sources of information, some of it being impersonal, such as knowledge gleaned from the mass media, and some of it personal in the sense of being inferred from the experiences or views of others with whom the individual interacts.

Particularly relevant for innovation is the individual's knowledge regarding what economists call "equations of motion." These equations represent an individual's perceptions of the link between an action or choice undertaken at time $t$, let us say $c_{t}$, and the distribution of possible consequences, say $y_{t+1}$. Consider the case of the IUD, which has only recently been introduced to Ghana. One equation of motion might describe the long-term effects of adopting the IUD on a woman's future state of health; associated with it would be her expectations and subjective uncertainties regarding these consequences. A Ghanaian woman who has heard of the IUD might wish to know about such health implications, and might be concerned with how her husband might react and what strategies she can draw upon in spousal negotiations. On these matters, rumors or confidences imparted by friends about the IUD might be distinguished from the information that the woman has distilled from media campaigns.

The information set $I_{i, t}$ thus includes a listing and description of other individuals $N_{i, t}$, a set of persons whose actions, communications, or perceived traits might help person $i$ to resolve uncertainties. The various members of $N_{i, t}$ may be sorted into groups (which themselves may overlap), some of which can be described as personal social networks. Social learning takes place interpersonally when the other actors in $N_{i, t}$ supply information that shapes person $i$ 's subjective beliefs about the equations of motion or other decision parameters. These actors 
may also function as resources to be sampled when person $i$ wishes to gather additional data.

Learning can be said to take place impersonally when, for example, knowledge is gleaned from the media. The boundary between interpersonal and impersonal sources is admittedly indistinct. Information obtained from the media is often passed on and evaluated through further social interaction (Hornik and McAnany 1998). Contacts with family planning programs often have both an interpersonal and an impersonal character.

The concept of social influence overlaps, to a degree, with the concepts of social learning and information sets, but is in many ways distinct. The term refers to the effects of interpersonal interactions that derive their power from factors that are intrinsically "social" and that are expressed in individuals' preferences and constraints as well as in their information sets. A vast literature in social psychology demonstrates the power of pressure toward social conformity in groups; see the comprehensive reviews by Moscovici (1985) and Cialdini and Trost (1998). A different form of social influence is expressed in concepts such as authority, power, and deference. In Ghana, men often exercise authority over women and define for them the limits of appropriate behavior. Senior women living in a household compound, such as the wife of a compound head, may exercise control over junior women. Senior men and women together may function as "gate-keepers," who restrict the movements of younger women (and to some degree, younger men) outside of the compound (see the description of northern Ghana by Adongo et al. 1997). In terms of our conceptual model, these hierarchical and power-based influences can be interpreted as additional constraints on individual behavior, or as a set of (psychic) costs facing the junior woman who contemplates innovative but deviant behavior.

In short, the reference groups and social networks embedded in $N_{i, t}$ can influence fertility through several distinct behavioral mechanisms. First, the in- 
formation they provide may expand the set of reproductive choices known to the woman. Second, behavior within $N_{i, t}$ can provide empirical demonstrations of the range of consequences that can follow from the adoption of a particular reproductive choice $c_{t}$, and may thereby shape the woman's subjective probability distributions and equations of motion. The third way in which $N_{i, t}$ enters is through effects on preferences, that is, through social influence effects, conformity pressures, and so on.

Suppose that woman $i$, having weighed the options and the attendant uncertainties, decides that she will adopt contraception at time $t$. Then, at time $t+1$, woman $i$ may play a new role as a reference point in the social networks of all other women, $N_{j, t+l}$, to which she belongs. For such women, $i$ 's experience may add to the accumulation of evidence in favor of modern contraceptive use. Whether this occurs depends on the degree to which woman $i$ 's contraceptive use is public knowledge, or is shielded by a screen of privacy that is lifted only when she decides to do so (Phillips et al. 1997a). The informational content of her experience also depends on how woman $i$ herself perceives the experience: she may find a newly adopted contraceptive method disagreeable or its health side effects disturbing and be willing to broadcast this view to others.

There should be no presumption that social effects must reinforce innovation. One gets the impression from research in developing countries that conversation about modern contraception is far more often negative than positive, with stories about extreme negative health repercussions of contraceptives often dominating the discussion (for Senegal, see Ngom 1995). Even in the contemporary United States, views regarding the potential health risks posed by contraceptive methods such as the pill or IUD have included considerable misperception, and this may well have resulted in long-term changes in the U.S. contraceptive method mix. Similar misconceptions are widespread in Ghana, as has been documented by Adibo (1992), Adongo et al. (1997), and Agyeman et al. (1996). Health scares, 
backlashes, the disapproval of local elites, the public failure of innovators-all these social effects frustrate rather than encourage innovation.

A social effects model emphasizing the role of networks $N_{i, t}$ is incomplete unless it addresses the issue of how such networks are formed and interlinked, and whether network membership is constant over time or varies with the lifecycle stage of the individual or other circumstances. Indeed, as will be demonstrated below, the dynamics implied by a diffusion model cannot be described unless that model can explain who is connected to whom. There are clearly linguistic and geographic boundaries on network formation, but there must also be other social and economic factors that determine $N_{i, t}$.

\section{The content of learning}

To this point, our discussion has emphasized the properties of contraceptive methods as the subject of information exchange, but social learning with respect to other issues may be equally or more important. One sees in Ghana the beginnings of a quantity-quality transition, whereby some families are having fewer children and investing more heavily in the education of each child. This innovation is more characteristic of urban than of rural areas, but even rural areas have begun to participate. To a rural couple, however, surrounded by family elders and living in what remains a largely traditional environment, the full implications of the new schooling and fertility strategies must seem uncertain indeed. How can they persuade themselves of the wisdom of this new course, if not by reference to the experiences and views of others who have already embarked on it?

In considering these two arenas of choice, one concerned with the costs of fertility regulation and the other with its long-term benefits, we see that the time spans required for outcome $y$ to be revealed may be very different. The health implications of using the pill or the IUD might be known in a matter of months or a few years; the risks and rewards of educating one's children, however, might 
not be known for decades. In the latter case, family $i$ might have to rely on the experiences of the very early adopters of the lower-fertility, higher-schooling strategy, and these adopters might be found in socioeconomic circumstances very different from its own. Family $i$ might also solicit the views and opinions of the other couples in its networks in an effort to better understand the educational "equations of motion." No one might have any direct experience to recount, but each couple in the network might relate stories heard at second-hand, and offer its predictions as to the likely outcomes of educating children.

The costs of sampling and network formation are also different in the two cases. Where contraception is concerned, there is always an element of privacy and potential embarrassment to consider. To engage in a discussion about such intimate matters, or even to broach the subject, may risk exposure to criticism or to social sanctions (Phillips et al. 1997a). We might distinguish between the fixed costs that person $i$ anticipates in first opening the subject with person $j$, and the costs of any subsequent discussion, which would presumably be lower. Costs probably assume less importance in obtaining information about schooling, this being a neutral subject open to free discussion. Knowledge about schooling might therefore have the character of a local public good, with information being exchanged easily among members of networks or wider social groups. Information about contraception, on the other hand, would more closely resemble a private good, available to the interested woman or couple only at an (implicit) price.

Whether it is information about schooling or about contraceptive methods that diffuses, new reproductive ideas will often be expressed through changes in contraceptive use. Trends in use, however, do not in themselves shed light on the nature of the information that has been exchanged. Offsetting positive and negative messages about contraception may both be exchanged, so that the net change in the prevalence of use is not revealing of the salience of the information that was communicated. Moreover, contraceptive use may serve only as a signal of 
the diffusion of more fundamental messages on the motivations for childrearing, and these messages need not have any direct connection to the properties of contraceptive methods themselves.

The foregoing discussion may help to clarify the differences between social learning regarding reproductive strategies, on the one hand, and learning in the context of agricultural innovation, on the other. As discussed in the next section, there is a long tradition of research on why farmers adopt or fail to adopt new agricultural practices, and this literature can be a fruitful source of insights and analogies. In the agricultural case, the treatment or choice $c_{t}$ made by one farmer (e.g., the adoption of a new high-yielding seed) can be easily observed by others, and one need wait only until the end of an agricultural season to know the outcome $y_{t+1}$. The village or some other geographically defined area can serve as the natural sample frame for each farmer, and within this frame a farmer can update his subjective beliefs without much consideration of sampling costs (Besley and Case 1993). By contrast, in settings such as northern Ghana, where modern contraception is thought to be socially threatening to men and women take pains to guard their privacy, the costs of information-gathering on contraception are probably high.

In both the agricultural and reproductive spheres, a problem arises in how to draw lessons from other actors who are situated in circumstances very different from one's own. ${ }^{2}$ Presumably what is relevant about the experiences of others is the link between their choices $c_{t}$ and their outcomes $y_{t+r}$. If the connections between choice and outcome are situation-specific, then it is difficult to know precisely how one family's experiments with a new reproductive strategy may prove relevant to another's. This may explain the apparent failure of fertility regulation practices to diffuse for many generations in some settings-for example, from European colonizers to native Africans, and from the upper to the lower social strata in Latin America (Rosero-Bixby and Casterline 1993). The 
value of information gained through network $N_{i, t}$ may therefore depend on the socioeconomic circumstances of network members relative to $i$ 's own circumstances.

Taken to the extreme, this would suggest that family $i$ should populate its networks with peers, i.e., with those most like itself in respect to the socioeconomic factors that affect the equations of motion. The difficulty, however, is that the homogeneous groups formed by this sampling strategy may not generate sufficient diversity of information. There may also be an advantage to sampling the experiences of non-peers, whose choices $c_{t}$ and outcomes $y_{t+1}$ may better reveal the full range of possible behaviors and consequences. Depending on the innovation in question, then, network $N_{i, t}$ may be composed both of peers and of nonpeers drawn from different social groups or strata. Again, the costs of forming network contacts must be taken into consideration, as it may be more difficult to forge a direct connection with another person who is distant in a socioeconomic or geographic sense.

Extending the analysis somewhat, we might consider the information on new reproductive strategies that is provided by impersonal and even fictional contacts, such as characters found on television (Faria and Potter 1994) or in the movies. These characters often embody new ideas and exemplify in their actions the conflicts between the old and new ways of thinking and behaving. They can provide models of new forms of consumption behavior, which may stimulate individual $i$ 's aspirations for various consumer goods. They also show how conflicts might be resolved and what negotiating tactics among spouses or relatives might prove successful.

We have sketched a point of view about rational individual decisionmakers who are faced with choices in new and uncertain environments. We have argued that they are likely to make decisions on the basis of information drawn from their personal social networks, local social organizations, influential elites, the mass media, and program personnel. Having made their own judgments as to the best reproductive strategy open to them, individuals contemplating innovative 
choices may find that others are positioned either to constrain or to facilitate such choices, acting on authority derived from roles such as spouse, compound gatekeeper, political or religious leader, or the like. The social dynamics of innovative behavior are therefore complex. Theory alone cannot provide clear guidance on the magnitude — or even the direction—of such social effects.

\section{AN OVERVIEW OF THE LITERATURE}

With these concepts in mind, we turn to the literature on diffusion modeling. A notable development in contemporary social science is the parallel evolution, across a number of disciplines, of ways of thinking about change that can be described in terms of diffusion. In other work (Montgomery and Casterline 1996), we have reviewed research in the fields of sociology, economics, and psychology; taken collectively, these fields have much to offer the demographer and program evaluator. In what follows, we will summarize the demographic research on diffusion and then, more briefly, review recent contributions from economics and sociology.

\section{The demographic literature}

Within demography, much of the current interest in diffusion effects can be traced to two influential studies: the family planning experiments conducted in 1964 in Taichung, Taiwan (see Palmore and Freedman 1969; Lu et al. 1967) and the European Fertility Study (see Knodel and van de Walle 1979; Watkins 1987). Curiously, of these two, the Taichung research is more persuasive on scientific grounds, but it is the European results that seem to have captured the imagination of the current generation of demographers.

The Taichung study, based on a randomized experiment and longitudinal follow-up, showed how the effects of direct program interventions targeted to some individuals can be spread to others who were not directly contacted by the program. These effects clearly illustrate how program impacts can be magnified 
by personal social networks. Retherford and Palmore (1983) provide a comprehensive review of the Taichung and other early Asian studies, emphasizing the role of such informal networks.

In contrast to the individual-level observations that formed the basis for the Taichung experiment, the European studies were based on aggregated areal data with a time-series dimension. Creatively using maps and other illustrative devices, Leasure (1962) and Lesthaeghe (1977) detected remarkable spatial, ethnic, and linguistic patterns in the fertility transitions of Spain and Belgium. The Belgian case (Lesthaeghe 1977) is particularly interesting, in that it documents clear linguistic boundaries to fertility change separating adjacent urban neighborhoods, this being suggestive of social barriers to information transmission. Other scholars (Knodel and van de Walle 1979; Cleland and Wilson 1987; Watkins 1987) put emphasis on the apparent simultaneity of fertility declines across Europe and on the rapid pace of demographic change once the transitions were engaged. ${ }^{3}$ The European studies suggest that the links between fertility decline and conventional measures of socioeconomic development are weak-a muchdisputed position (Galloway et al. 1994; Richards 1977) — thereby arriving at diffusion processes and "ideational change" as residual explanations for fertility decline.

The European evidence, although intriguing, is far from conclusive. Rapid and discontinuous change in fertility is consistent with a diffusion dynamic, but it is also consistent with conventional fertility models (Retherford 1985). The fact that fertility change observes linguistic or cultural boundaries is likewise consistent both with diffusion and with alternative perspectives. Furthermore, as we established above, a well-formulated diffusion model must reserve a place for conventional social and economic factors. The notion that diffusion constitutes a wholly distinct class of explanation does not withstand scrutiny.

Recent empirical research has continued to add findings supportive of diffu- 
sion hypotheses. In the longitudinal analysis mentioned above, Montgomery and Casterline (1993) present suggestive results for Taiwan based on aggregate crosssectional and time-series data. Similar approaches were followed by Rosero-Bixby and Casterline (1994), Tolnay (1995), Land and Deane (1991), and Munshi and Myaux (1998). These authors acknowledge a discomfort with aggregate data and argue that proper tests require multi-level data on individuals and their social networks.

Until very recently, only one effort had been made to assemble such data: the pioneering work of Everett Rogers and colleagues (summarized in Rogers and Kincaid 1981) on social networks and contraceptive use in rural Korea. ${ }^{4}$ The Korean data, although rich in network detail, are cross-sectional and therefore cannot furnish the basis for tests of diffusion. Subsequent research by Valente and colleagues in Cameroon (Valente et al. 1997), by Entwisle and colleagues in Thailand (Entwisle and Godley 1998), by Watkins and colleagues in Kenya (Watkins et al. 1995; Green 1998), coupled with our own efforts in Ghana (summarized briefly below and in Montgomery and Zhao 1998) have contributed new cross-sectional studies of social networks and contraceptive use. Until the longitudinal dimension of these studies can be filled in, they too must be regarded as making suggestive rather than definitive contributions.

\section{Other research traditions}

Social effects, broadly defined, have long been at the center of sociological theory and research. See, for example, the review of research in social psychology in Cialdini and Trost (1998) and the theoretical essays in Hedström and Swedberg (1998). More directly relevant to the research agenda described here is the study of social networks, which in itself is a well-developed subfield of sociology. It is the domain of two journals, Social Networks and Connections, and the central preoccupation of a literature too vast to summarize here. Recent articles that draw out the implications for diffusion are Marsden and Friedkin (1993) and 
Strang (1991); a recent summary is Marsden (1998). Granovetter and Soong (1983, 1986) developed analytic methods that Valente (1995) later adapted to the study of contraceptive use. Branches of social and cognitive psychology (Carley 1998; Nowak et al. 1990) have also been concerned with social learning processes.

The literature on diffusion in agricultural economics has likewise been a major source of hypotheses and analogies (see Griliches 1957 for an early contribution and Feder et al. 1985 for an insightful review). As noted above, one can see parallels in the situation of poor farmers considering adoption of high-yielding seeds and of poor men and women considering the adoption of contraception. The analogies are sometimes superficial or inexact, but they often merit serious consideration. Besley and Case (1993), Munshi (1994), and Foster and Rosenzweig (1994) have analyzed agricultural decisions in a manner that has clear applicability to demographic innovation.

Outside agricultural economics, however, interest in diffusion and related social effects is a comparatively recent phenomenon. In the 1990s, such research has belatedly flourished as a number of economists pursued analyses of social learning, information cascades, social interaction, and diffusion, often in models in which individuals are assumed to be identical apart from the information they possess. ${ }^{5}$ Much of this literature is theoretical, a notable exception being McFadden and Train (1996).

A closely related literature is concerned with "interdependent preferences" (see Pollak 1976; Alessie and Kapteyn 1991; and Kapteyn et al. 1997). The theme pursued by these authors is the interconnection among individuals of demands for consumer goods. In making decisions about consumption, individuals are assumed to be influenced by the consumption behavior exhibited in their reference groups. This is a potentially fruitful area for demographic research, in the sense that consumption aspirations may have an indirect yet fundamental influence on the demand for children. 


\section{A DYNAMiC Simulation MODEL}

Having highlighted the central roles of social networks and information exchange within the theory of diffusion processes, we now ask how these roles might be revealed in empirical data. The key question is whether the effects of diffusion can be identified and the magnitudes estimated. Formidable difficulties confront this task. Indeed, in the view of some skeptics, the effort to estimate diffusion models must founder on an intractable complex of problems. If the skeptics are right and there is little hope of estimating proper causal models, then the diffusion hypothesis will likely remain no more than a tantalizing theoretical possibility.

The skeptics have powerful arguments on their side-see Durlauf and Walker (1998) for an insightful presentation—but it would be premature to cede the field to them. The essence of the problem is that when a diffusion model is specified in full generality, it admits too many possibilities and lacks sufficient structure for diffusion effects to be precisely and confidently identified. Additional social-structural assumptions are therefore needed; but, of course, these assumptions cannot be imposed arbitrarily. The structural assumptions must be grounded in detailed, specific knowledge of the local social context. The need for local detail then precludes certain types of empirical investigation, for example, large national samples involving hundreds of heterogeneous clusters and communities. It implies a rather different mode of research, one that is based in wellunderstood communities or regions.

Given research designs such as these, three related modes of inquiry are required. First, careful, demographically realistic analytic simulations are required to draw out the data needs of diffusion modeling and to highlight the empirical regularities that demand closest attention. Second, since so little is known about social networks in developing countries, rich descriptive information is needed 
on these networks in the local context. Third, the properties of newly developed econometric techniques need to be carefully assessed, first through application to simulated data and then to actual data from the study communities.

With these aims in mind, in what follows we present the early returns from an analytic simulation model based, to the extent possible, on the Ghanaian context. The model is constructed so as to expose the dynamic implications of different social network configurations. In the simulation context, one can manipulate the key parameters describing these networks and then investigate the effects on such outcome measures as contraceptive use or knowledge. This approach is useful in understanding the data that will be required for effective empirical work.

In the next section, we present some of the required data: empirical information from southern Ghana on the nature, extent, and variety of social networks. The third and final item on the empirical agenda- to devise and test appropriate econometric methods-raises technical issues that lie outside the scope of the present paper. We leave this item to future research.

\section{A dynamic model}

Montgomery and Zhao (1998) have formulated a dynamic decision model in which individual reproductive decisions are forward-looking and are made with respect to an evolving set of information. The individual decision model is set in a social networks context, and information is allowed to circulate among decisionmakers through their network ties. Each decisionmaker is endowed with an initial set of information, but revises that information in the light of such information exchange. This approach respects the multi-level and dynamic nature of diffusion processes.

The individual decision model is invested with features that are broadly similar to those of Ghanaian reproductive decisionmaking. In one respect, however, the model remains incomplete. The major area requiring further work is to 
accommodate motives for birth spacing in the model as well as motives for fertility limitation. The results to be presented below are therefore only descriptive and suggestive.

\section{Learning through social networks}

We now illustrate how such an individual decision model can be linked to social networks and provide a tool for studying diffusion. Our purpose is mainly to show how social effects might express themselves; we have not yet incorporated empirical data on Ghana's social networks in the model.

We begin with a benchmark case in which women differ in their views of contraceptive costs, but do not exchange information or revise these views through social network contacts. (The model underlying this analysis is complex, and the details are relegated to the Appendix.) Figure 1 shows the simulated distributions of births and surviving children under the benchmark assumptions. (The figure summarizes a simulation of the reproductive careers of 1000 women.) The simulated total fertility rate is 5.85, a reasonable value in the Ghanaian context, and agespecific birth rates (not shown) are also consistent with empirical data. However, because no allowance has yet been made for birth-spacing motivations, the implied schedules of contraceptive use differ from those in Ghana (see the Appendix).

We can compare this benchmark case to one in which women learn about contraceptive costs through social network exchanges. The following example may be helpful by way of illustration. Imagine that each woman $i$ begins her reproductive career with an initial belief about contraceptive costs. Also imagine that each woman is endowed with a fixed reference group of five other women, selected randomly from the population, each of whom has her own initial belief regarding costs. Denote this reference group or information network by $N_{i}$. Woman $i$ may be a reference point for other women, who can gather information from her, but she herself refers only to the members of $N_{i}$. 
Figure 1 Children ever born and surviving: Benchmark model

Ideal family size $=5$. Contraception costs uniform $(0,5)$

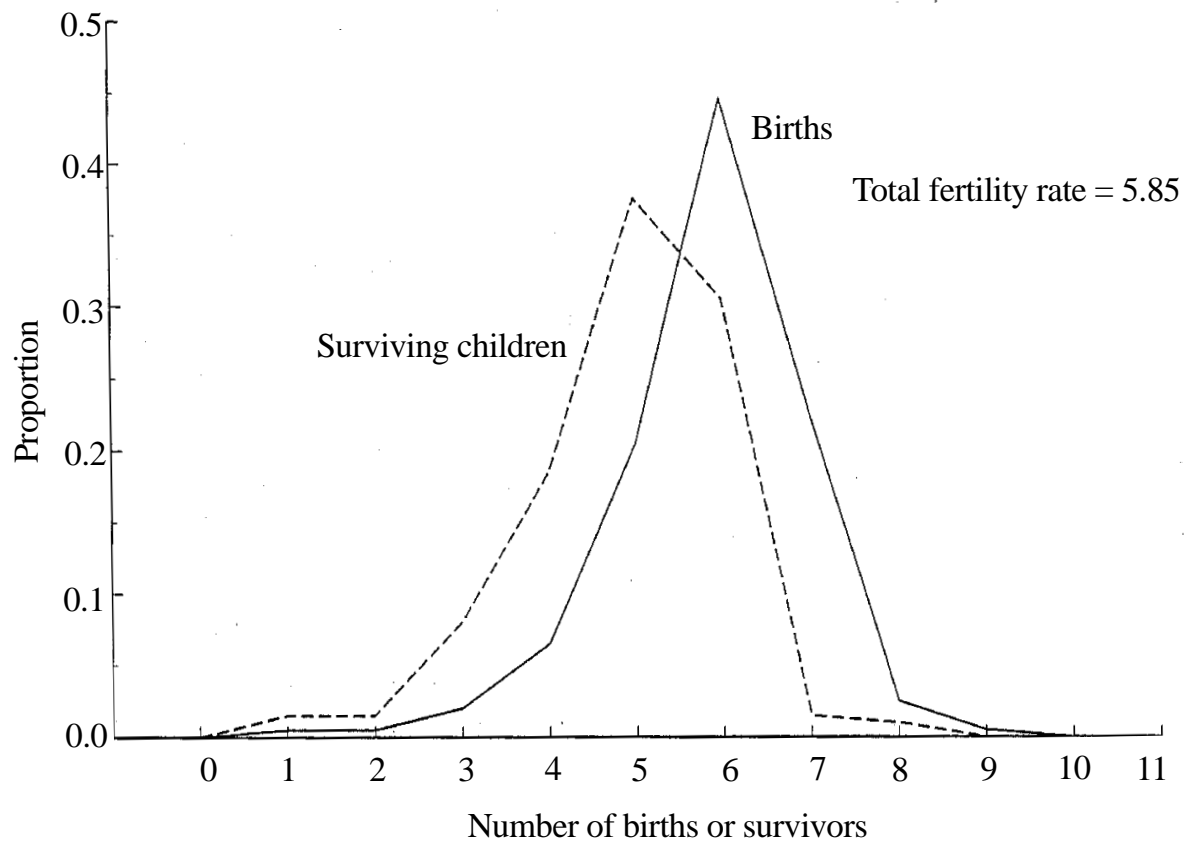

At intervals, woman $i$ collects information about contraception from her reference group $N_{i}$ and, on the basis of this, updates her own view of costs. We assume for simplicity that in the interim between updates, woman $i$ ignores the possibility of all future changes in cost beliefs.

Consider one way in which information about contraceptive costs might be revised. A substantial literature in psychology (see Montgomery 1998 for a review) suggests that negative information is given disproportionate weight in the formation of perceptions and the evaluation of risks. How might such a notion be relevant to the diffusion of contraceptive use? We might think of negative information about contraceptive costs as being summarized, for woman $i$, in the most extreme view of costs that is held by a member of her reference group. 
Figure 2a Convergence in information on contraceptive costs

Initial distribution is uniform $(0,5)$

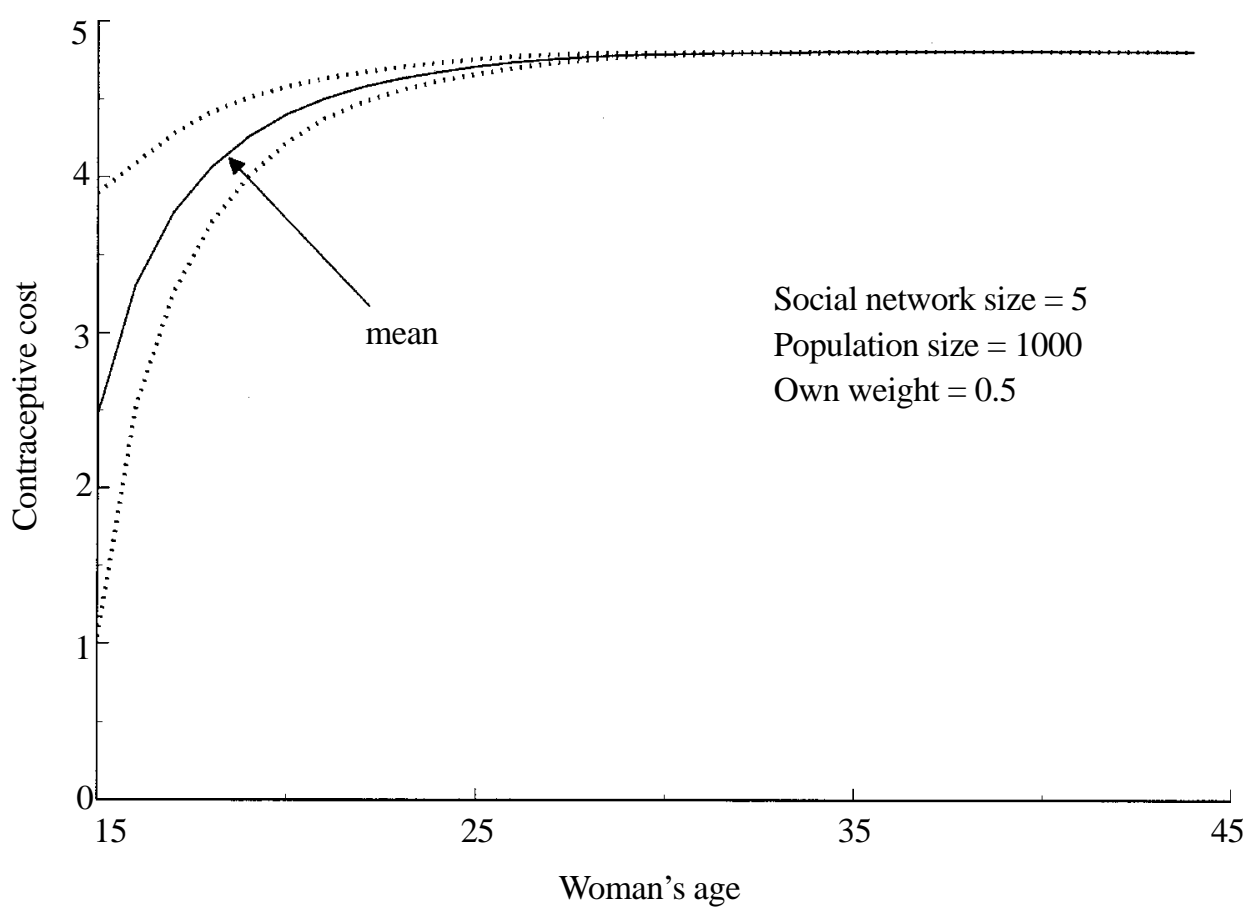

Suppose that woman $i$ adjusts her perceived costs by averaging her own beliefs and the worst (maximum cost) belief.

Figure 2 shows how, with successive rounds of updating (we assume that updating takes place yearly), negative information about contraception comes to dominate women's views. In Figure $2 \mathrm{a}$, the woman is assumed simply to average her current belief about costs with the most extreme views found in her reference group. This simple updating model results in a near-consensus about the high costs of contraceptive use. The solid line in the figure shows the mean perceived costs in the population of women, and the dotted lines show the range of views from one standard deviation below the mean to one standard deviation above. 
Figure 2b Convergence in information on contraceptive costs

Initial distribution is uniform $(0,5)$

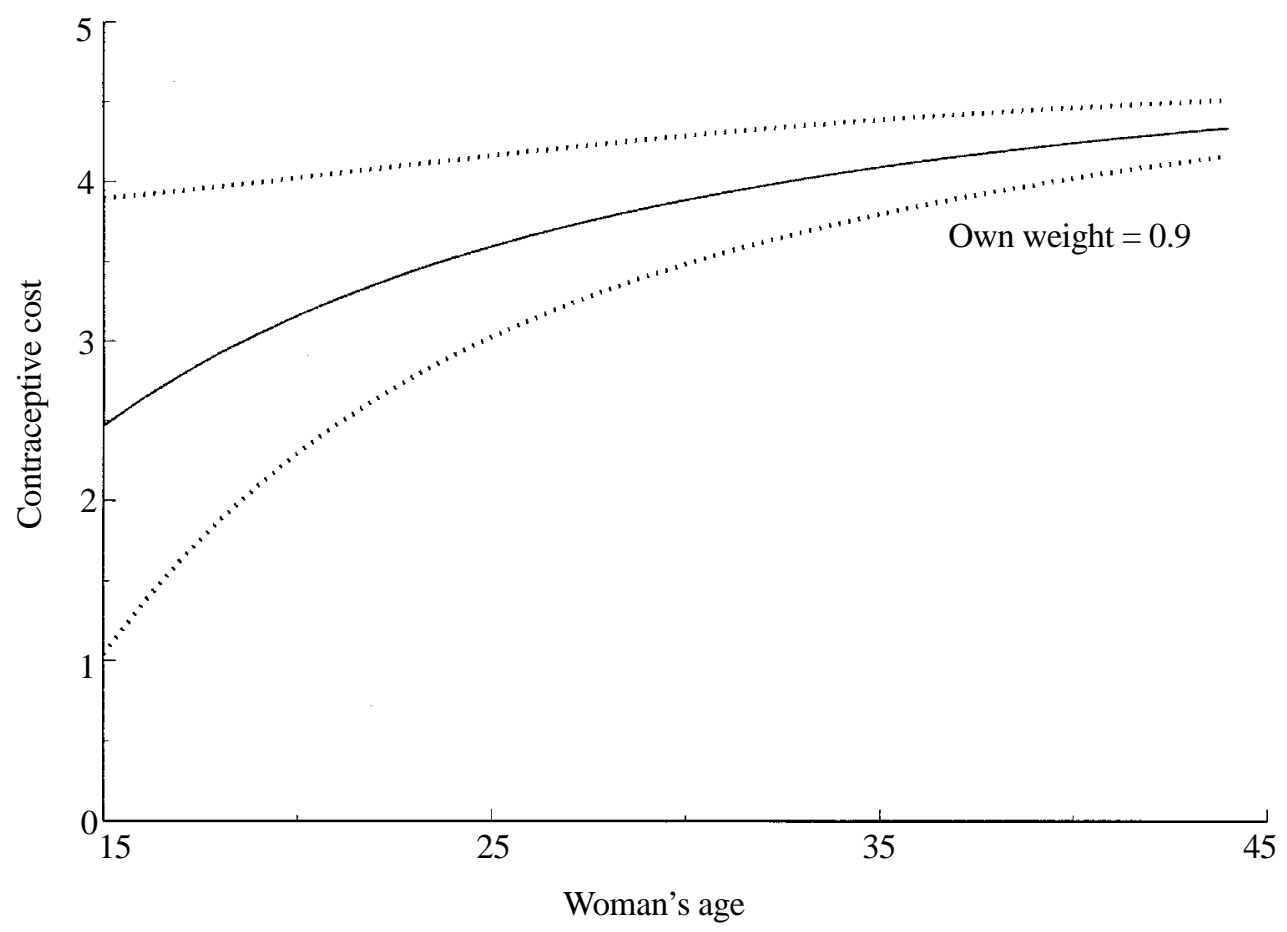

To understand this figure, it is useful to know that the initial contraceptive cost is represented by a number randomly drawn for each woman from a uniform $(0,5)$ distribution with mean 2.5 . The mean and standard deviation bounds are the left-most values indicated in Figure 2a. At the first round of updating, the woman focuses on the most extreme information about contraceptive costs that can be found in her reference group. The expected value of this maximum in a reference group of size $n$ is $5 n /(n+1)$, and with $n=5$, this is obviously greater than the overall mean of 2.5. Thus, we should expect that perceptions of contraceptive costs will tend to display an upward trend as information is exchanged. Note that as each woman $i$ revises her own views of contraceptive costs based on her own reference group $N_{i}$, other women for whom woman $i$ is a reference point will 
Figure 2c Convergence in information on contraceptive costs

Initial distribution is uniform $(0,5)$

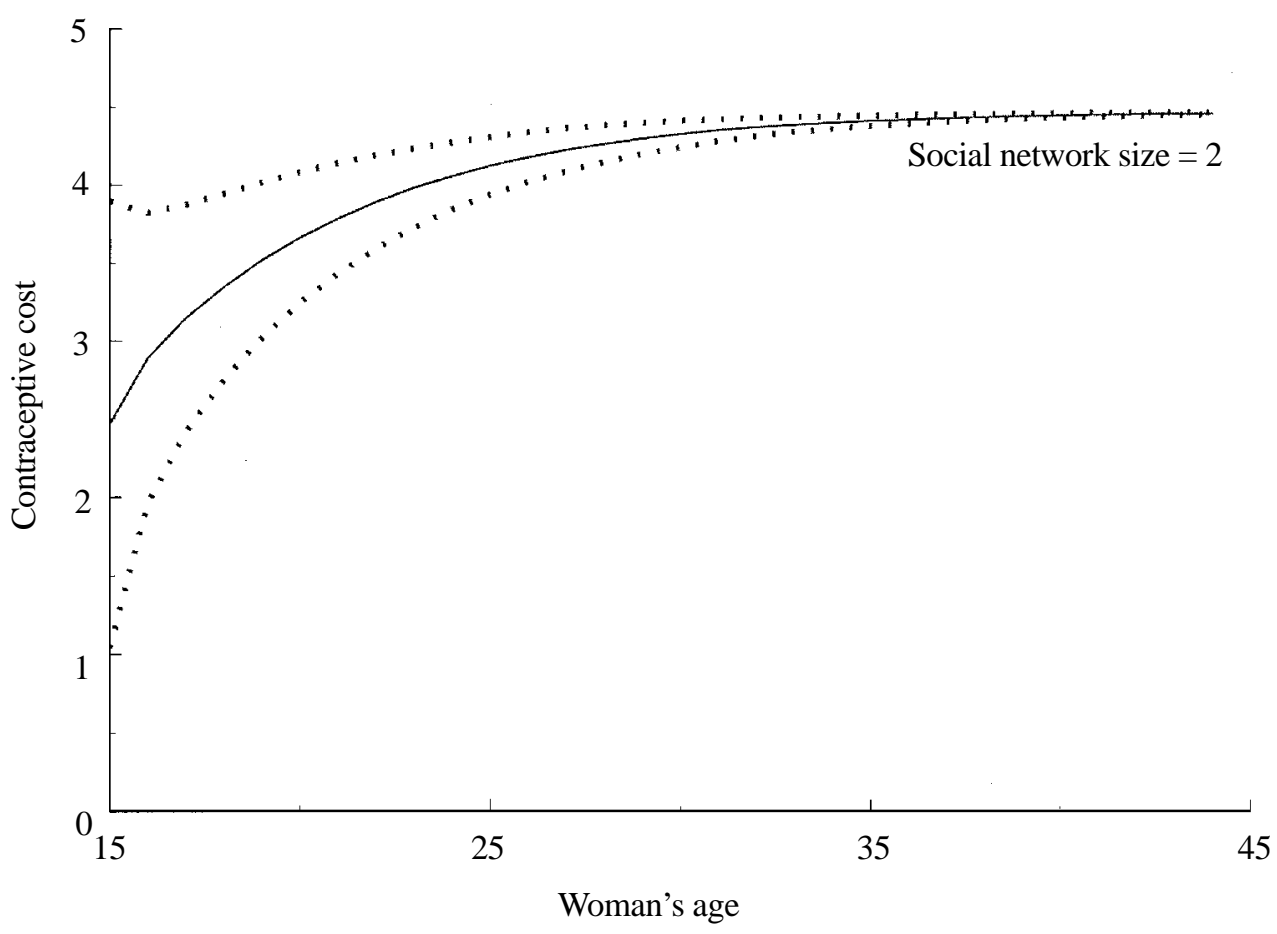

revise their views, in part with reference to her. The consequence is that in the population as a whole, there is a decreasing variance in perceptions of contraceptive costs, as indicated in the convergence of the standard deviation bounds about the mean.

To continue with the example, Figure $2 b$ shows the influence of the weight that women place on their own views as against the negative testimony of their reference groups. In the previous figure, women gave equal weight to their personal views and the most extreme view found in their reference group. In Figure $2 \mathrm{~b}$, by contrast, women pay systematically less attention to the beliefs of their reference groups. This difference is evident in the slower upward revision of views about costs and in the persistent of variation in the population. 
Figure 2c shows how network size might influence the distribution of views. (We return here to the assumption of equal weights.) Suppose that reference groups were composed of only two instead of five women. The expected value of the most negative view found in the smaller reference group would necessarily be lower than the expected value in a larger reference group. As a result, there is again a slower increase in the mean perception of costs than was true in Figure $2 \mathrm{a}$, as well as somewhat more persistence of variation in views.

How might these differences in information transmission affect contraceptive use? In Figure 3, we plot simulated contraceptive prevalence under two scenarios, first for the case in which women are randomly allocated their views of contraceptive costs and do not "learn" or revise those views over their reproductive careers, and second, for the case in which they annually revise their views by reference to a network of size five (equally weighting their views and those of others). As can be seen, the implied differences in contraceptive prevalence are considerable. ${ }^{6}$ All women with five surviving children, the ideal in this simulation, use contraception at ages 31 and younger; but contraceptive prevalence remains higher in the case of no learning than it does in the case of revisions based on the average of own views and those of the reference group.

The simulation model is clearly illustrative, its main point being to demonstrate the subtleties of the diffusion perspective. Evidently, the details of behavior and social organization will matter: that is, precisely how individual social networks are formed, how extensive they are, and what information is exchanged within them can decisively shape aggregate trajectories of innovation. These critical modeling issues cannot be decided on the basis of theory alone. What is required is dedicated empirical work.

\section{GHANAIAN SOCIAL NETWORKS}

No one data collection exercise could hope to gather all relevant elements of 
Figure 3 Differences in contraceptive use due to learning

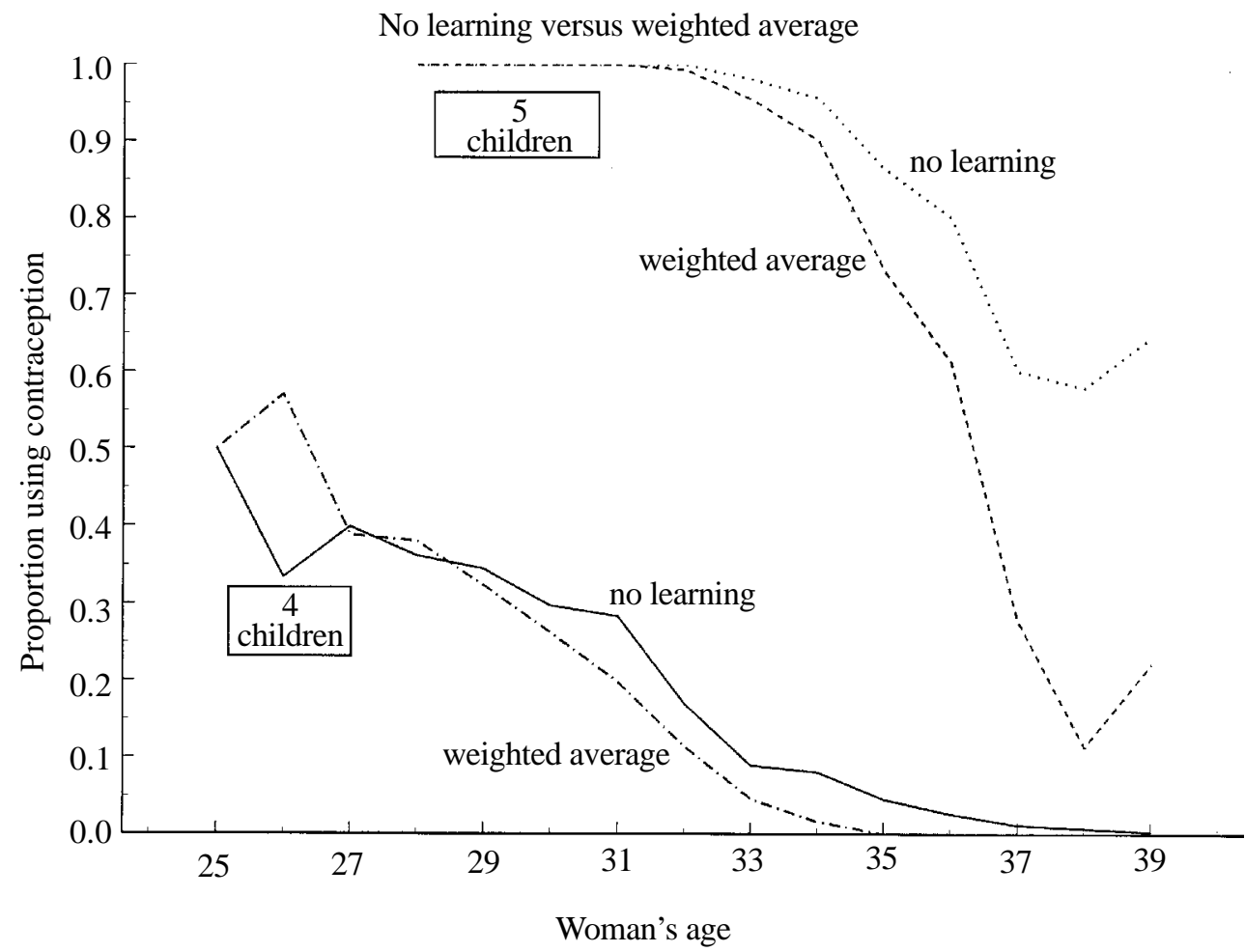

individual information sets, the social structure in which individuals are embedded, the messages communicated along their social networks, and the new thinking stimulated by the operation of programs and the media. It is feasible, however, to concentrate research attention on a few of the dimensions believed to be critical to reproductive change. In 1995, our research team gathered data in four sites in the Central and Greater Accra regions of southern Ghana (Agyeman et al. 1996). The purpose was twofold: to develop a portrait of the social organization of these sites, and to measure both formal and informal social interaction concerning modern contraception. Multiple data collection methodologies were employed, including semi-structured interviews, focus group discussions, surveys, and ethnographic 
methods. Here we provide glimpses of these data, in order to demonstrate that measurement of social interaction is feasible and that the measures are associated with contraceptive use in ways that are consistent with the diffusion perspective.

Contraceptive use is still uncommon in these study sites. Although a majority of reproductive-age adults have heard of modern methods such as the pill, injectables, and the condom, only about one-quarter of women report having used a modern method and only 10 percent report using at the time of the survey. As is often the case in West Africa, the corresponding fractions are higher for men.

In regard to local social structure, Table 1 summarizes the main elements of political, social, and religious organization. (Additional discussion and detailed community profiles are presented in Agyeman et al. 1996.) A striking feature is the large number of organizations in rather small communities. These organizations include various church fellowships and associations, Town Development Committees, the 31st December Women's Movement, PTAs, Youth Associations, and Women's Welfare Associations. Several of these organizations are national in character. In the ethnic Akan sites (Frami and Dutch Komenda), there is in addition an Asafo Company, a traditional military organization for men. Some of these organizations are gender-based, and their objectives center around improving the socioeconomic status of community members. All sites save Tubaman have a bewildering variety of religious associations, from Orthodox Protestant groups to Roman Catholics to all manner of syncretic churches and traditional religions. Some of the organizations listed in Table 1 also facilitate extra-community interaction. The Football Club in Amanfro and the 31st December Women's Movement, for example, bring their members into contact with people from all over Ghana. And all of the religious organizations, including the Muslim organizations in Tubaman, influence information flow to and from the communities. Finally, in all sites exposure to the influence of radio and, to a lesser extent, television is pervasive. 
Table 1 Characteristics of study communities and number of local influentials

Dutch

Frami Tubaman Amanfro Komenda

Community characteristics

Ethnicity

Lineage type

Ecology

Local influentials

Chief(s)

Queen mother(s)

Linguists

Chief fisherman or farmer

Asafo

Religious leaders

Heads of basic education

Town development committee

Unit chairmen

31st December women's movement leaders

Assemblyman

PTA chairman

Other influentials

Health and family planning providers
Denkyira

Matrilineal Patrilineal

Inland, rural Inland, rural
Adangbe
Ga Patrilineal Matrilineal Inland, Coastal, rural peri-urban 
The novel aspect of this exploratory research was the collection of social network data at both the individual and the community level. Our strategy was to collect data from each respondent on the characteristics of each of his or her network members. We first inquired about outside-compound contacts, using responses to the question "With whom do you talk most often?" to identify up to four network contacts. ${ }^{7}$ Our intention was to emphasize interactions other than those with spouses and near kin, who are likely to reside in the respondent's compound. (No doubt these near-at-hand daily interactions are also important; we will examine them more intensively in the upcoming longitudinal research.) The general demographic characteristics of each network member were determined (from the respondent's report) and we then probed to learn of conversations and other exchanges regarding contraception. In a second segment of the questionnaire, we asked about any other persons with whom modern contraception had been discussed; persons co-residing in the compound were eligible to be included in this second battery of questions.

We were not aware of any equivalent efforts to gather social network data in southern Ghana and, at the outset, could not rule out the possibility that respondents would be reluctant to report on network members. In the event, such fears proved to be unfounded. The respondents reported on a relatively large number of network members (see Table 2): an average of about three persons in the first block of questions (those outside the compound "with whom you talk most often") and an average of about four persons (results not shown) in the two blocks of questions combined. Virtually no one failed to identify network members, and over 90 percent volunteered information on two or more network members. Some 50 percent of the respondents reported on the maximum of four network members permitted in the first block of questions (those outside the compound "with whom you talk most often"). Overall, this must be regarded as confirmation that this strategy of inquiry can succeed in southern Ghana, at least 
Table 2 Percent distribution of number of outside-of-compound network members, by sex of respondent

\begin{tabular}{lccc}
\hline & $\begin{array}{c}\text { Men } \\
(\mathbf{N = 2 8 8})\end{array}$ & $\begin{array}{c}\text { Women } \\
(\mathbf{N = 3 1 2})\end{array}$ & $\begin{array}{c}\text { Total } \\
(\mathbf{N = 6 0 0 )}\end{array}$ \\
\hline $\begin{array}{l}\text { Those "with whom you talk most often } \\
\text { outside this compound" }\end{array}$ & & \\
$\quad$ No one & 2 & 3 & 2 \\
1 person & 3 & 12 & 7 \\
2 people & 20 & 20 & 20 \\
3 people & 26 & 15 & 21 \\
4 people & 49 & 50 & 50 \\
Mean network size & 3.2 & 3.0 & 3.1 \\
\hline
\end{tabular}

to the extent of respondents cooperating in the basic task of reporting on their fellow network members. A final point about Table 2 is that men reported on slightly more network members than did women.

Respondents were asked about a selected set of demographic and socioeconomic characteristics of their network members. Table 3 shows the characteristics of outside-compound network members, with attention to the differences between network members and the respondents. Of course we expect to find a good deal of homogeneity in personal networks, but we were also interested to see what degree of heterogeneity characterizes them for men and women. The table indicates that outside-compound social networks are: (1) heterogeneous with respect to age, with high proportions of respondents reporting both older and younger network contacts; (2) almost entirely same-sex in character; (3) composed of both kin and non-kin, the latter being more prevalent; and (4) heterogeneous with respect to schooling and, to some degree, with respect to residence as well. There are surprisingly few male-female differences in these networks, with perhaps the most interesting finding being the higher proportions of outside-village contacts among women. We suspect that these contacts may be the result of 
Table 3 Characteristics of outside-of-compound network members in relation to respondent $(\mathrm{R})$, by sex of respondent (percentage distributions)

\begin{tabular}{|c|c|c|c|}
\hline & Men & Women & Total \\
\hline \multicolumn{4}{|l|}{ Age } \\
\hline Younger than $\mathrm{R}$ & 44 & 38 & 41 \\
\hline Same age & 11 & 9 & 10 \\
\hline Older than $\mathrm{R}$ & 45 & 53 & 49 \\
\hline \multicolumn{4}{|l|}{ Sex } \\
\hline Male & 94 & 7 & 51 \\
\hline Female & 5 & 93 & 49 \\
\hline \multicolumn{4}{|l|}{ Relationship } \\
\hline Kin & 20 & 38 & 29 \\
\hline Non-kin & 80 & 62 & 71 \\
\hline \multicolumn{4}{|l|}{ Schooling* } \\
\hline Less than $\mathrm{R}$ & 28 & 31 & 29 \\
\hline Same as R & 51 & 47 & 49 \\
\hline More than $\mathrm{R}$ & 20 & 20 & 20 \\
\hline \multicolumn{4}{|l|}{ Residence } \\
\hline Same village & 87 & 76 & 81 \\
\hline Other village & 5 & 10 & 8 \\
\hline Town or city & 7 & 13 & 10 \\
\hline \multicolumn{4}{|c|}{ Most recent conversation } \\
\hline Today & 45 & 50 & 48 \\
\hline Yesterday & 27 & 20 & 24 \\
\hline This week & 14 & 11 & 12 \\
\hline Previously & 13 & 19 & 16 \\
\hline
\end{tabular}

* Not ascertained for 2 percent of cases.

women's roles in trading and marketing.

The conversations about contraception that occur in these personal networks are described in Table 4. This table is stratified according to the number of network members reported by the respondent. The reason for stratifying is that, with everything else being equal, a respondent who identifies more network members is more likely to have discussed contraception with at least one of those 
Table 4 Discussion of contraception with outside-of-compound network members, by ever-use of contraception, sex of respondent, and number of network members (percentages)

$\begin{array}{ccc}\begin{array}{c}\text { Never used } \\ \text { modern } \\ \text { contraception }\end{array} & \begin{array}{c}\text { Ever used } \\ \text { modern } \\ \text { Men Women }\end{array} & \begin{array}{c}\text { Men Womention } \\ \end{array}\end{array}$

Number of members

with whom contraception

was discussed:

Discussed with one

No discussion

Discussed with one

Discussed with both

No discussion

Discussed with one

Discussed with two

Discussed with all

No discussion

Discussed with one

Discussed with two

Discussed with three

Discussed with all

$25 \quad 23$

$61 \quad 71$

$8 \quad 11$

$31 \quad 18$

One network member

Two network members

$29 \quad 27$

$$
18
$$$$
27
$$

35

45

15

61

$55 \quad 30$

40

18

Three network members

$\begin{array}{rr}68 & 61 \\ 12 & 11 \\ 9 & 11 \\ 12 & 17\end{array}$

29

36

46

55

$17 \quad 9$

14

11

29

$43 \quad 18$

18

Four network members

$\begin{array}{rr}64 & 53 \\ 10 & 23 \\ 6 & 8 \\ 7 & 8 \\ 12 & 8\end{array}$

$\begin{array}{ll}13 & 23 \\ 13 & 23 \\ 20 & 18 \\ 20 & 18 \\ 34 & 18\end{array}$

members. Consider the "Total" columns and those respondents who mentioned one network contact. Among these respondents, 29 percent of men and 27 percent of women reported having had a discussion with that person about modern contraception. Among those mentioning two network contacts, 40 percent of men reported having had a conversation with both persons and 55 percent $(40+15)$ with at least one person. Considering the majority of respondents, those who 
Table 5 Summary of contraceptive discussion with network members, by everuse of contraception and respondent's sex

\begin{tabular}{|c|c|c|c|c|c|c|}
\hline & \multicolumn{2}{|c|}{$\begin{array}{c}\text { Never used } \\
\text { modern } \\
\text { contraception }\end{array}$} & \multicolumn{2}{|c|}{$\begin{array}{c}\begin{array}{c}\text { Ever used } \\
\text { modern }\end{array} \\
\text { contraception } \\
\end{array}$} & \multicolumn{2}{|c|}{ Total } \\
\hline & $\overline{\text { Men }}$ & $\overline{\text { Women }}$ & $\overline{\text { Men }}$ & $\overline{\text { Women }}$ & $\overline{\text { Men }}$ & Women \\
\hline $\begin{array}{l}\text { Mean number } \\
\text { with whom discussed }\end{array}$ & 0.8 & 0.7 & 2.0 & 1.5 & 1.4 & 0.9 \\
\hline $\begin{array}{l}\text { Mean percentage } \\
\text { with whom discussed }\end{array}$ & 26 & 24 & 61 & 46 & 43 & 31 \\
\hline
\end{tabular}

reported on two to four network members, over one-half report conversations about contraception with at least one person. Interestingly, men were somewhat more likely than women to report conversations about contraception with at least one of their network partners. For both sexes, however, such conversations are relatively common. It seems that there is a good deal of interpersonal interaction about contraception in these villages.

Table 4 also examines the association between interpersonal interaction regarding contraception and use of modern contraception. Analysis of precisely this linkage is the long-term goal of the research program, motivated by the theory and other research described earlier. The materials at hand are limited to a single cross-section snapshot of a dynamic relationship; we cannot hope on this basis to identify the causal impact of network interaction on contraceptive behavior. Until we have gathered the appropriate prospective data, analysis of the sort presented in Table 4 is nevertheless of interest, for two reasons. First, it contributes to our evaluation of the validity of this data collection strategy: we assume that those who have used modern contraception are more likely to have discussed it with friends and relatives, and therefore we would question the validity of the reports of conversations about modern contraception if these were not reported 
Table 6 Contraceptive discussion with types of network members, by ever-use of contraception and respondent's sex (percentages)

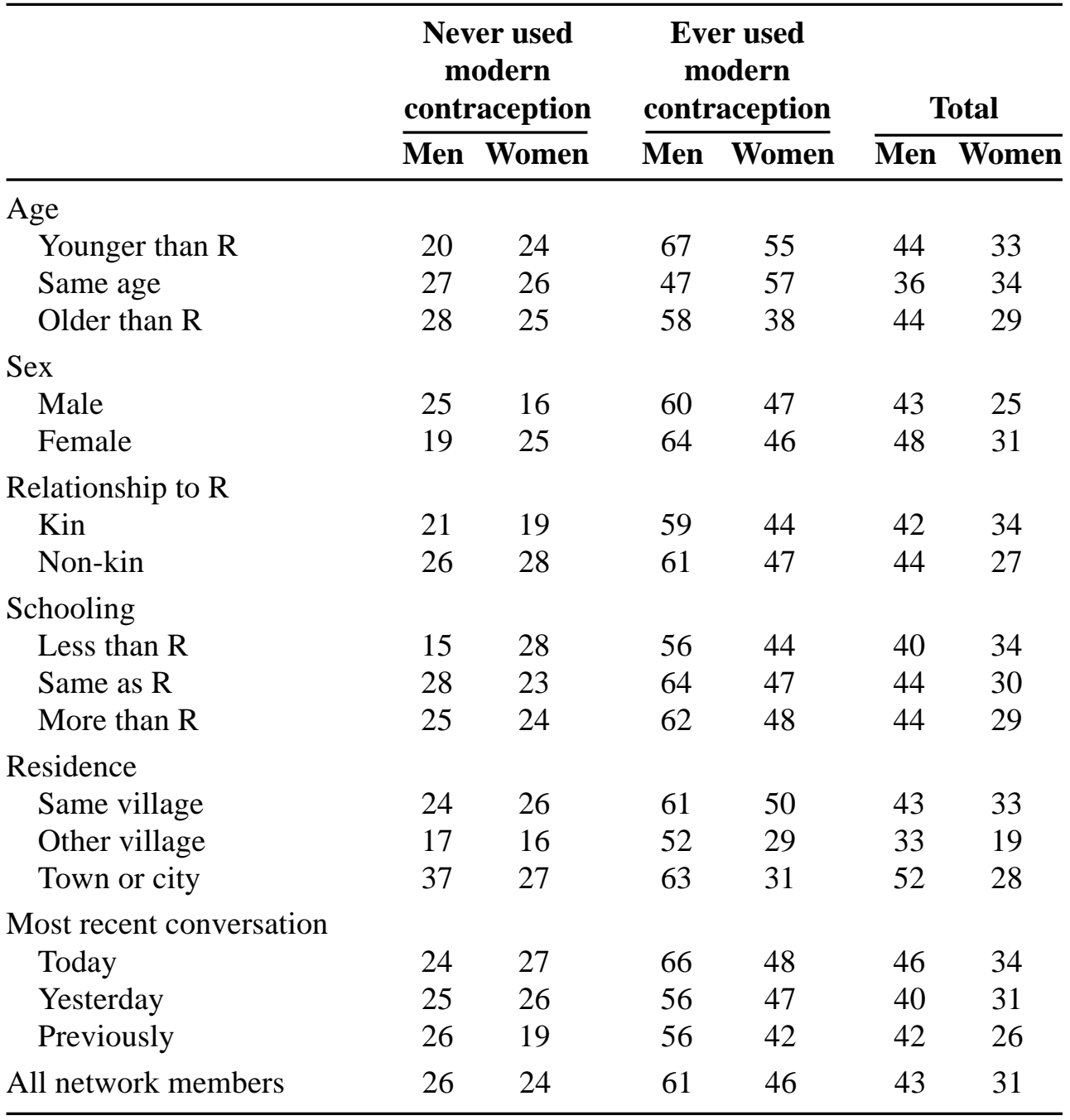

to be more common among ever-users. Second, the figures in Table 4 give a rough indication of the direction and strength of interpersonal diffusion.

Almost without exception, respondents who have ever used modern contraception are much more likely to report having conversations about contracep- 
tion with fellow network members. The association between interpersonal interaction and use is strongly positive. Table 5 distills the findings in two summary indicators: for contraceptive users and non-users, the mean number and the mean percentage of persons with whom conversations have occurred. For example, among men, ever-users have discussed modern contraception with 2.0 network members on average, as against 0.8 network members among never-users. These results are strikingly similar to the findings of Valente et al. (1997) and Watkins et al. (1995).

Further details on the likelihood of conversations about modern contraception occurring are given in Table 6. The likelihood that contraception is discussed is shown according to characteristics of the network members (as well as the sex and contraceptive use status of the respondent). This table offers rich material for addressing a host of questions about social interaction and contraception. One can, for example, ask questions about the association between network heterogeneity and discussions of contraception. Granovetter's (1973) argument that "weak ties" are more conducive to the diffusion of innovative ideas implies that information about contraception is more likely to be exchanged in outside-village network contacts and among non-kin. The figures in Table 6 do not show such limits on contraceptive information exchange; it seems to occur with outside contacts and those inside the village, between kin and non-kin, among those with greater schooling than the respondent and with less, and so on. Socioeconomic factors may well facilitate or constrain discussion of contraception, but identifying the precise patterns will require further research.

\section{CONCLUSIONS}

The term "diffusion" has appeared in the literature on fertility transition with increasing frequency during the past two decades. This paper has provided a more precise definition of diffusion than is the norm in the literature, and has considered how diffusion effects might be expressed and what they might imply for the timing and pace of fertility change. 
As used here, diffusion refers to a process in which individuals' decisionsin this instance, decisions bearing on reproduction-are affected by the knowledge, attitudes, and behaviors of others with whom they come in contact. This contact might occur through face-to-face social interaction with kin, friends, and neighbors or, at the other extreme, through interactions at a distance through the mass media. Two fundamental behavioral mechanisms account for such diffusion effects: social learning and social influence. Social learning refers to the acquisition of information from others. The information might have to do with a new technology, or with the health, social, and economic consequences of decisions. In the case of fertility, individuals might learn from others about the availability of a new contraceptive, or about health side effects of certain contraceptives, or about the apparent gains and losses from having fewer children and investing in their schooling. Social influence refers to the power that individuals exercise over each other through authority, deference, and pressures for social conformity. In the case of fertility, spouses and other kin may forbid practice of contraception (and have the means to enforce this prohibition), or individuals may be reluctant to depart from community reproductive practices out of fears of social marginalization.

Although social learning and social influence undoubtedly operate in every setting, it is likely that their effects are more powerful in environments of uncertainty, where the costs and benefits of decisions are poorly understood. The uncertainty can be induced by forces such as demographic changes (reductions in mortality), rapid introduction of technological innovations, transformations in the economy, the improvement of transportation and communication infrastructure, and the expanded provision of public services by government and private agencies. Such forces, often perceived by individuals as being out of their control, leave them both bewildered and insecure about appropriate behavioral responses. In such environments, it is natural to seek guidance from others, whether as sources of essential information or as models of how to respond to the changes that are underway. 
This paper has emphasized the role of individual networks and local social structure, but as others have argued (e.g., Bongaarts and Watkins 1996), national and even international networks should also be considered. The political and bureaucratic commitments needed to sustain delivery of family planning and health services are no doubt strengthened by an interlocking series of networks. These serve to link, at one end, international donors and providers of technical assistance with groups of in-country policymakers and program managers, at the other end. Such connections are brought to the fore in Watkins's analysis of the development of population policy in Kenya (Watkins and Hodgson 1998).

It has been a common practice in the research literature of the past two decades on fertility transition to set diffusionist theory against conventional theory. This opposition is incompatible with the model developed in this paper, in which diffusion effects and the effects of demographic, social, and economic factors are inseparable. Diffusion dynamics - the expression of social learning and social influence-are one means through which the fundamental factors operate.

This is a central point of the argument we have developed, and perhaps can be made clearer by illustration. Consider the response of fertility to mortality decline. According to the argument developed here, the magnitude of the population-level response depends in part on what individuals conclude from their own observations and from their discussions with others about improvements in survival chances. Similarly, emerging employment opportunities for women will alter reproductive strategies only to the extent that households are made aware of these opportunities through mass media channels and informal social interaction, and to the extent that social constraints do not prevent women from pursuing these opportunities. Much the same logic can be applied to many conventional explanatory variables.

If the causal process leading to fertility decline operates in this way, then clearly it makes little sense to impose a conceptual boundary between diffusion 
effects and the effects of exogenous economic and social variables; and there can be no support for the view that the two sets of effects are alternative and competing explanations for fertility decline. Rather, diffusion dynamics occupy a position of a different character in the causal model of fertility decline: they condition or mediate the effects of other variables, either dampening or amplifying their effects. Diffusion and conventional explanatory variables can coexist comfortably in a well-specified theory of social change.

If one accepts this view, then the research challenge is to make an accurate and balanced assessment of the nature and magnitude of diffusion effects. Two strategies for carrying out such an assessment are presented in this paper. The first strategy uses micro-simulations in which an individual woman's contraceptive practice is responsive to the knowledge and practice of contraception in her social network. Despite the simple structure of the simulation model employed here, it clearly illustrates the subtleties of the diffusion perspective.

In the simulation model, the likelihood of using contraception is influenced by contact with other persons. The simulations illustrate how the magnitude of the influence depends on the size of a woman's social network and on the weight she attaches to the information she receives from network partners. Evidently, the details of behavior and social organization matter: how individual social networks are formed, how extensive they are, and what information is exchanged within them can decisively shape aggregate trajectories of innovation.

These parameters are inputs to the simulations and, given the present state of knowledge, the choice of values is arbitrary. The simulations will become more informative to the extent that the parameters correctly describe social processes in specific settings. The key information is not yet known for societies that are now undergoing transition from high to low fertility, and hence the social network and related parameters must be measured through dedicated empirical studies. 
The second strategy involves collection of the necessary primary data, as we have done through fieldwork initiated in Ghana in 1995. Descriptive results from our first attempts to measure social networks and link them to contraception were presented. The exercise provides considerable encouragement that empirical work on this topic is feasible. In the focused inquiry about social networks, virtually none of the Ghanaian respondents failed to identify a network member, and over 90 percent volunteered information on two or more members. The reported characteristics of these network relationships seem reasonable, in particular showing male-female differences that are plausible in Ghanaian society The data also reveal that conversations about contraception are relatively common in the sampled communities, having occurred in roughly one-half of the network relationships (and, interestingly, more frequently for men than women). Finally, a strong positive association is apparent between such conversations about contraception and the likelihood of having used modern contraception.

This empirical association is consistent with the theory developed in the first part of this paper, but it would be premature to claim empirical verification of the theory. If the decision to use contraception can be attributed in part to social diffusion effects, then contraceptive users should report more social interaction about contraception than non-users, just as observed in the Ghanaian data. But this association can also be explained by a process in which individuals make a decision to use contraception in isolation, uninfluenced by the contraceptive attitudes and behaviors of members of their social network, and then, having adopted contraception, proceed to discuss it with those members. Individuals might even decide to affiliate themselves with others who are known to have made the same innovative choice. That is, the presence of contraceptive users in an individual's social network, and the discussion of contraception with friends and neighbors, might follow from, rather than precede, the decision to use contraception. Either causal process is compatible with the Ghanaian data. 
With reflection, it becomes clear that this matter cannot be resolved with a single cross-section study measuring social interaction patterns and contraceptive attitudes and behaviors. Indeed, short of pure experimental design, no strategy will yield an unambiguous portrait of the causal structure. But if social interaction patterns and contraceptive use are jointly tracked over time, the analytical capacity to disentangle stimulus from response is significantly strengthened. Building on the exploratory materials described here, we have established such a longitudinal research program in Ghana. The overarching aim of this program is to make an empirical assessment of the scope and scale of diffusion effects on reproductive behavior, with particular attention to the practice of contraception. The design will also permit a host of corollary issues to be addressed, including: the density and composition of social networks and how these vary by sex, age, schooling, ethnicity, social organization of the community, and other variables; the content of discussion about modern contraception and, in particular, the relative weight of positive and negative messages; the effect of local health and family planning services on the prevalence and content of discussion about contraception and related issues; and the prevalence of discussion about modern contraception per se as against discussion of broader issues concerning the costs and benefits of childbearing and childrearing. Each of these issues can have considerable bearing on the direction and magnitude of diffusion effects on fertility.

The significance of this work for the design and evaluation of programs is clear. If diffusion dynamics have substantial effects on reproductive decisions, then surely the design of programs should be sensitive to this fact and, indeed, exploit it to the extent possible. Programs should nurture positive diffusion effects and deliberately counter negative diffusion effects. In a similar vein, efforts to evaluate program impact will be biased if they ignore the "spillover" and "multiplier" effects that social diffusion dynamics produce; hence practicable methods for accounting for diffusion effects in program evaluation must be developed. 


\section{APPENDIX}

In what follows, we sketch the main assumptions and methods employed in the simulation model described above. Montgomery and Zhao (1998) gives additional details. We focus on women and women's social networks in this simulation.

\section{The individual model}

The full reproductive span for a woman ranges from age $t_{0}$ to $T$, where we take $t_{0}$ to be age 15 and $T$ to be age 45 . Within this reproductive span, age $t$ is indexed in months. The terminal age $T$ is defined to be the oldest age at which conception probabilities are non-zero. Women first marry at age $t_{m}$, an age that is randomly drawn from a first marriage age schedule for Ghana. We assume that no reproduction takes place before $t_{m}$ and also assume that all marriages remain intact until the terminal reproductive age $T$. (We hope to generalize future versions of the model to accommodate marriage dissolution and remarriage.) Each woman possesses an ideal family size $\breve{s}$, which can be regarded as a target number

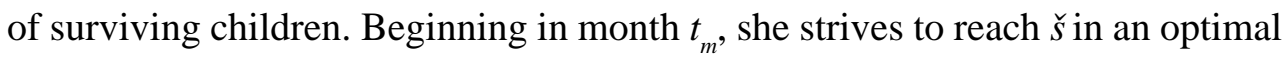
fashion over the course of her reproductive career.

Because reproductive outcomes cannot be perfectly controlled, a woman may either fall short in her attempt to meet the target $\check{s}$ or exceed the target. She may be prevented from reaching $\breve{s}$ by infant or child mortality, which remains high in Ghana. The risk of such mortality is expressed in an age schedule of mortality hazards $m_{a}$ for a child of age $a$, with the values of $m_{a}$ drawn from life tables based on Demographic and Health Survey data (Ghana Statistical Service and Macro International 1994). The woman can also overshoot $\breve{s}$ through unintended conceptions, or she can fail to conceive and thereby undershoot $\breve{s}$.

In striving to reach $\breve{s}$, the woman makes use of a single control variable, denoted by $c_{t}$, which indicates a decision to use modern contraception in month $t$ 
(that is, $c_{t}=1$ ) or not. Regulating fertility in this way is not costless, however, and modern contraceptive use entails two sorts of costs. First, each month of contraceptive use exacts a penalty $c c$, the level of which is expressed in terms of the woman's utility. Second, contraceptive use also exposes the woman to the risk of health side effects. Having such health problems (a situation expressed by $h_{t}=1$ ) reduces the woman's monthly utility by an amount $h c$. If she uses contraception, she faces the probability $p h$ of contracting such a side effect. A woman who has such a side effect can abandon contraceptive use; if she does, her monthly probability of recovery from the side effect is given by $r n$. If she continues to use contraception, however, the monthly probability of recovery is given by $r c<r n$.

Of course, contraceptive use also promises utility benefits in that it reduces the probability of conception. The age schedule of fecundability is denoted by $f n_{t}$, and a woman who uses modern contraception faces reduced risks of conception, as expressed in the schedule $f c_{t}=\beta \cdot f n_{t}$ with $\beta<1$. If she conceives, there is a 9-month gestation period to be endured (months of pregnancy are indexed by $g_{t}$ ) and, following birth, a 17-month period of postpartum amenorrhea and sexual abstinence.

To summarize, the state variables for the model are as follows. The number of surviving children, as of mother's age $t$, is denoted by $s_{t}$. The number of months since her last birth is given by $a_{t}$ and the survival status of the last birth is indicated by $l_{t}$, where $l_{t}=1$ means that the child is still alive. (These two state variables are assigned default values for women who have not yet had any births.) The indicator $h_{t}$ expresses the woman's health status at age $t$, with $h_{t}=1$ meaning that she has a health side effect that is traceable to contraceptive use. Nonpregnant women have gestation indicator $g_{t}=0$, whereas $g_{t}$ indexes the month of pregnancy for pregnant women.

By "optimal," we mean that the woman is assumed to act so as to maximize utility over her reproductive lifetime. Lifetime utility is given by the sum- 
mation of a sequence of age-specific utility functions $u_{t}\left(s_{t}, a_{t}, l_{t}, h_{t}, g_{t}, \theta\right)$, and a terminal value function $U\left(s_{T}, a_{T}, l_{T}, h_{T}, g_{T}, \theta\right)$, with $\theta$ a vector of decision parameters. Let the full state vector be given by $y_{t}=\left(s_{t}, a_{t}, l_{t}, h_{t}, g_{t}\right)$. In this notation, the expected utility derived over a reproductive career is

$$
E_{t_{m}}\left(\sum_{t=t_{m}}^{T-1} u_{t}\left(y_{t}, c_{t}, \theta\right)+U\left(y_{T}, \theta\right)\right)
$$

where $E_{t_{m}}$ denotes expectations formulated as of the woman's age at marriage $t_{m}$.

Since the decision horizon is finite, ending at $T$, the states are discretevalued, and the (single) control variable is also discrete, optimal contraceptive decisions are readily determined by the method of backwards recursion. Montgomery (1989) develops a number of demographic models in this vein; also see Wolpin (1998) for a simple example involving child mortality, and Rust (1994) for a review of the related econometric literature.

\section{Implementing the decision model}

To proceed, we require functional forms for the period utility function $u_{t}\left(y_{t}\right.$ $\theta$ ) and the terminal value function $U\left(y_{T}, \theta\right)$. For simplicity, we define the period utility function to be

$$
u_{t}=-\left(s_{t}-\check{s}\right)^{2}-h_{t} \cdot h c-c_{t} \cdot c c,
$$

in which deviations from the family size ideal $\breve{s}$ are penalized in a quadratic and symmetric fashion. Such symmetry is perhaps implausible, in that one might expect smaller penalties for exceeding $\check{s}$ in societies like Ghana's that have been organized to manage high fertility. (We will explore non-symmetric versions of $u_{t}$ in future work.) Note that period utility $u_{t}$ is not discounted in this formulation, although doing so would be an easy generalization.

As for the terminal value function,

$$
U=-\kappa E_{T}\left(s_{T}-\check{s}\right)^{2}-E_{T}\left(\sum_{v=T}^{\infty} h_{v} \cdot h c \mid c_{T}=0\right) \text {. }
$$


The factor $\kappa>1$ is employed to inflate the value of $U$ in relation to period utility $u_{t}$. Expectations are required in defining $U$ because women may be pregnant $\left(g_{T}>0\right)$ upon entering period $T$ and the ensuing birth may or may not survive. In addition, women can enter $T$ with a health condition $\left(h_{T}=1\right)$ that was the result of prior contraceptive use and this condition may persist for some time even in the absence of contraceptive use. The expected health cost can be summarized as equal to $h c / r n$ if $h_{T}=1$ and as equal to zero otherwise.

Neither $u_{t}$ nor $U$ contains terms that reflect motivations for birth spacing; rather, each is specified only in numbers of surviving children. Two spacing motivations will be investigated in future work. First, we will explore whether postpartum sexual abstinence can be viewed as a traditional contraceptive method for which modern methods might substitute. Second, it may be possible to generalize the model so that the mortality risks faced by children depend on the preceding birth interval, thus adding another motivation for birth spacing. For the moment, however, we have chosen a single mortality schedule $m_{a}$ that depends on the child's age but not on the preceding birth interval.

To implement the model, we are also required to select a schedule of fecundability by age, $f n_{t}$, choose a value for contraceptive efficacy $\beta$, and specify the trio of transition probabilities that are associated with health $(p h, r c, r n)$. The utility parameters $h c, c c$, and $\kappa$ must also be specified.

The chosen parameter values are as follows for the baseline runs. The direct contraceptive cost parameter $c c=2.5$; the health cost parameter $h c=2.5$; the monthly probability of contracting a health side effect if using contraception is $p h=.25$; and the monthly probability of recovery is $r c=.1$ when contraception continues to be used and $r n=.9$ if it is not used. The weighting factor $\kappa$ for the terminal value function is set to $\kappa=10$. Contraceptive efficacy $\beta=.05$, and the mortality schedule is chosen so that ${ }_{5} q_{0}$ matches the values for the central region of Ghana. See Montgomery and Zhao (1998) for further discussion. 


\section{Baseline results without networks}

Using a baseline set of parameter values and demographic schedules, we have simulated contraceptive decisions and reproductive outcomes for a birth cohort of women whose ideal family size is $\breve{s}=5$ children. Women differ in their initial views of the direct costs of contraception, such that they are distributed uniformly across the range of possible costs from low to high. The model assumes that for each woman $i$, the parameter $c c_{i}$ is drawn randomly from a uniform distribution with range [0,5]. The mean value of $c c_{i}$ is thus 2.5 . We assume that each woman retains her initial view of costs (the value of $c c_{i}$ ) throughout her reproductive career. In this benchmark model, then, no learning about contraceptive costs takes place.

Although the fertility rates produced by such a model are encouragingly similar to those reported in the Ghana DHS, the profiles of contraceptive use implied by the model (not shown) are distinct from those seen in the DHS data. Given an ideal family size $\breve{s}=5$, the model predicts the following: essentially no contraceptive use among women with three or fewer surviving children; some "precautionary" contraceptive use among those with four children (see Montgomery 1989 for a discussion of the precautionary motive in dynamic models of target fertility); and, initially at least, universal contraceptive use among women with five or more surviving children. Holding the number of surviving children constant at four or more, contraceptive use declines with the woman's age, this being a consequence of declining fecundability, which reduces the risks of nonuse. The Ghana DHS, by contrast, shows appreciable contraceptive use among women with fewer surviving children than their expressed ideal, behavior that must reflect motives for birth spacing not captured in our simulation model. The DHS data also show that at no parity is contraceptive use universal; rather, the 
peak probability of use for women exposed to conception risk is about .35. Clearly, to match these features of the DHS profiles, the simulation model must be generalized to include spacing motivations.

\section{Modeling heterogeneity and learning}

We now compare the benchmark case to one in which women learn about contraceptive costs through social network exchanges. The following example may be helpful by way of illustration. Imagine that each woman $i$ is endowed with an initial value for $c c_{i}$ precisely as above. Also imagine that each woman $i$ is endowed with a fixed reference group of five other women, selected randomly from the population, each with her own initial value of $c c$. Denote this reference group or information network by $N_{i}$. Woman $i$ may be a reference point for other women, who draw information from her, but she herself refers only to the members of $N_{i}$.

At intervals, woman $i$ draws information about contraception from her reference group $N_{i}$ and, on the basis of this, updates her own views of costs, generating a new value of $c c_{i}$. For example, having first updated her cost view $\left(c c_{i}\right)$ at age $t_{1}$, she proceeds to solve again the dynamic decision problem, which is to maximize

$$
E_{t_{1}}\left(\sum_{t=t_{1}}^{T-1} u_{t}\left(y_{t}, c_{t}, \theta\right)+U\left(y_{T}, \theta\right)\right)
$$

taking as given the value of the state vector $y_{t_{1}}$. The procedure is repeated upon the next infusion of information at $t_{1}+\Delta$. In the interim between $t_{1}$ and $t_{1}+\Delta$, woman $i$ acts according to the revised dynamic decision rules that are based, in part, on her revised views of contraceptive costs. We assume for simplicity that in the interim, woman $i$ behaves myopically in the sense that she ignores the possibility of all future changes in such costs. 


\section{Notes}

1 Research on Ghana involves John Casterline, Mark Montgomery, and James Phillips at the Population Council; in Ghana, Fred Binka and Alex Nazzar of the Navrongo Health Research Centre and, in a parallel research program in the south, Dominic Agyeman of the University of Cape Coast. Preliminary findings are presented in Phillips et al. (1997b) and Agyeman et al. (1996). Similar research is being conducted by Susan Watkins and colleagues in Kenya and Malawi (see Watkins et al. 1995 for preliminary results) and a comparable effort is in progress in northeastern Thailand (Entwisle and Godley 1998).

2 Manski (1993a) has developed an interesting model of social learning from peers, but a key assumption is that individuals are identical in all dimensions affecting the equations of motion.

3 Bongaarts and Watkins (1996) see similar patterns in contemporary developing countries.

4 These data were later reanalyzed by Montgomery and Chung (forthcoming) and Valente (1995).

5 See, among others, Arrow (1994), Arthur and Lane (1992), Banerjee (1992, 1993), Besley and Case (1993), Bikhchandandi et al. (1992), Conlisk (1980, 1996), Ellison and Fudenberg (1993, 1995), Foster and Rosenzweig (1994), Kohler (1997), Manski (1993a,b), McFadden and Train (1996), Munshi (1994), Munshi and Myaux (1998), and Shiller (1995).

6 As discussed in the Appendix, the figures show a reduction in contraceptive use with age, holding constant the number of surviving children. This 
decline is the result of declining fecundability, which reduces motivation for contraceptive use.

7 In earlier pilot research, we allowed for more than four network partners. The decision to truncate the list at four is the product of a compromise: the lower the truncation point, the greater the potential bias; but the greater the number of network partners considered, the greater the risk of respondent fatigue and perfunctory replies. In the longitudinal research currently in the field, we first obtain a full list of network partners and then make detailed inquiries for four of these. This alternative approach will permit (limited) analyses of truncation bias.

\section{References}

Adibo, M. 1992. "Conceptions and misconceptions: Community views on family planning." Technical Report, Health Research Unit, Ministry of Health, Accra, Ghana.

Adongo, Philip B. et al. 1997. "Cultural factors constraining the introduction of family planning among the Kassena-Nankana of northern Ghana." Social Science and Medicine 45(12): 1789-1804.

Agyeman, Dominic K. et al. 1996. "Social structure and the diffusion of fertility behavior." Final Report submitted to the Rockefeller Foundation.

Alessie, R. and Arie Kapteyn. 1991. "Habit formation, interdependent preferences and demographic effects in the Almost Ideal Demand System." Economic Journal 101: 404-419.

Arrow, Kenneth. 1994. "Methodological individualism and social knowledge." American Economic Review 84(2): 1-9.

Arthur, W. Brian and David A. Lane. 1992. "Information contagion.” Working 
Paper 91-05-026, The Santa Fe Institute, Economics Research Program.

Banerjee, Abhijit. 1992. “A simple model of herd behavior.” Quarterly Journal of Economics 107(3): 797-817.

1993. "The economics of rumors." Review of Economic Studies 60: 309327.

Besley, Timothy and Anne Case. 1993. "Taking learning seriously: A diffusion model for HYV cotton." Unpublished paper, Research Program in Development Studies, Princeton University.

Bikhchandandi, Sushil, David Hirshleifer, and Ivo Welch. 1992. "A theory of fads, fashion, custom and cultural change as information cascades." Journal of Political Economy 100(5): 992-1026.

Bongaarts, John and Judith Bruce. 1995. "The causes of unmet need for contraception and the social content of services." Studies in Family Planning 26(2): 57-75.

Bongaarts, John and Susan Cotts Watkins. 1996. "Social interactions and contemporary fertility transitions." Population and Development Review 22(4): 639-682.

Carley, Kathleen M. 1998. "Learning and using new ideas: A socio-cognitive perspective." Paper presented to the National Academy of Sciences workshop, "The Social Dynamics of Fertility Change in Developing Countries," Washington, D. C.

Cialdini, Robert B. and Melanie R. Trost. 1998. "Social influence: Social norms, conformity, compliance.” In D. T. Gilbert, S. T. Fiske, and G. Lindzey (eds.), The Handbook of Social Psychology, Volume II, pp. 151-192. New York: McGraw-Hill.

Cleland, John and Christopher Wilson. 1987. "Demand theories of the fertility transition: An iconoclastic view." Population Studies 41: 5-30. 
Conlisk, John. 1980. "Costly optimizers versus cheap imitators.” Journal of Economic Behavior and Organization 1: 275-293.

1996. "Why bounded rationality?" Journal of Economic Literature 34: $669-700$.

Durlauf, Steven N. and James R. Walker. 1998. "Economic theory and diffusion models." Paper presented to the National Academy of Sciences workshop, "The Social Dynamics of Fertility Change in Developing Countries," Washington, D. C.

Ellison, Glenn and Drew Fudenberg. 1993. "Rules of thumb for social learning." Journal of Political Economy 101(4): 612-643.

1995. "Word-of-mouth communication and social learning." Quarterly Journal of Economics 110(1): 93-125.

Entwisle, Barbara and Jenny Godley. 1998. "Village networks and patterns of contraceptive choice." Paper presented to the National Academy of Sciences workshop, "The Social Dynamics of Fertility Change in Developing Countries," Washington, D. C.

Faria, Vilmar and Joseph Potter. 1994. "Television, telenovelas, and fertility change in northeast Brazil." Paper presented to the IUSSP Seminar on Values and Fertility Change, Sion, Switzerland.

Feder, G., R. Just, and D. Zilberman. 1985. "Adoption of agricultural innovations in developing countries: A survey." Economic Development and Cultural Change 33(2): 255-298.

Foster, Andrew and Mark Rosenzweig. 1994. "Learning by doing and learning from others: Human capital and technical change in agriculture." Paper presented to the Northeast Universities Development Conference, Economic Growth Center, Yale University.

Galloway, Patrick R., Eugene A. Hammel, and Ronald D. Lee. 1994. "Fertility 
decline in Prussia 1875 to 1910: A pooled cross-section, time-series analysis." Population Studies 48(1): 135-158.

Ghana Statistical Service and Macro International. 1994. "Demographic and Health Survey 1993." Technical Report, Ghana Statistical Service and Macro International, Calverton, Md.

Granovetter, Mark. 1973. "The strength of weak ties." American Journal of Sociology 78(6): 1360-1380.

Granovetter, Mark and R. Soong. 1983. "Threshold models of diffusion and collective behavior.” Journal of Mathematical Sociology 9: 165-179.

. 1986. "Threshold models of interpersonal effects in consumer demand." Journal of Economic Behavior and Organization 7: 83-99.

Green, Steven R. 1998. "Normative versus instrumental functions: Evidence of social network differentiation among rural Kenyan men." Paper presented at the 18th meeting of the Sunbelt Conference on Social Networks, Sitges, Spain.

Griliches, Zvi. 1957. "Hybrid corn: An exploration in the economics of technological change." Econometrica 25: 501-522.

Hedström, Peter and Richard Swedberg. 1998. "Social mechanisms: An introductory essay." In Peter Hedström and Richard Swedberg (eds.), Social Mechanisms: An Analytical Approach to Social Theory, pp. 1-31, Cambridge: Cambridge University Press.

Hornik, Robert and Emile McAnany. 1998. "Mass media and fertility change." Paper presented to the National Academy of Sciences workshop, "The Social Dynamics of Fertility Change in Developing Countries," Washington, D. C.

Kapteyn, Arie, Sara van de Geer, Huib van de Stadt, and Tom Wansbeek. 1997. "Interdependent preferences: An econometric analysis." Journal of Applied Econometrics 12: 665-686. 
Knodel, John and Etienne van de Walle. 1979. "Lessons from the past: Policy implications of historical fertility studies." Population and Development Review 5(2): 217-245.

Kohler, Hans-Peter. 1997. "Fertility and social interaction: An economic approach." $\mathrm{Ph}$. D. thesis, University of California at Berkeley, Economics Department.

Land, Kenneth C. and Glenn Deane. 1991. "On the large-sample estimation of regression models with spatial or network effects terms: A two-stage least squares approach." Paper presented at the Annual Meeting of the American Sociological Association, Cincinnati.

Leasure, J. William 1962. "Factors involved in the decline of fertility in Spain, 1900-1950.” Ph. D. thesis, Princeton University.

Lesthaeghe, Ron J. 1977. The Decline of Belgian Fertility, 1800-1970. Princeton: Princeton University Press.

Lu, L., H.-C. Chen, and L.-P. Chow. 1967. "An experimental study of the effect of group meetings on the acceptance of family planning in Taiwan." Journal of Social Issues 23(4): 171-177.

Manski, Charles F. 1993a. "Dynamic choice in social settings: Learning from the experiences of others." Journal of Econometrics 58: 121-136.

1993b. "Identification of endogenous social effects: The reflection problem.” Review of Economic Studies 60: 531-542.

Marsden, Peter V. 1998. "Diffusion through social networks." Paper presented to the National Academy of Sciences workshop, "The Social Dynamics of Fertility Change in Developing Countries," Washington, D. C.

Marsden Peter V. and Noah E. Friedkin. 1993. "Network studies of social influence." Sociological Methods and Research 22(1): 127-151.

Mason, Karen O. 1997. "Explaining fertility transitions." Demography 34(4): 443-454. 
McFadden, Daniel L. and Kenneth E. Train. 1996. "Consumers' evaluation of new products: Learning from self and others." Journal of Political Economy 104(4): 683-703.

Montgomery, Mark R. 1989. "Dynamic behavioural models of contraceptive use." Journal of Biosocial Sciences, Supplement to Volume 11: 17-40.

. 1998. "Learning and lags in mortality perceptions." In Mark R. Montgomery and Barney Cohen (eds.), From Death to Birth: Mortality Decline and Reproductive Change, pp. 112-137. Washington, D. C.: National Academy Press.

Montgomery, Mark R. and John B. Casterline. 1993. "The diffusion of fertility control in Taiwan: Evidence from pooled cross-section, time-series models." Population Studies 47(3): 457-479.

- 1996. "Social learning, social influence, and new models of fertility." Population and Development Review, Supplement to Volume 22: 151-175.

Montgomery, Mark R. and Woojin S. Chung. Forthcoming. "Social networks and the diffusion of fertility control in Korea." In Richard Leete (ed.), Cultural and Temporal Variations in Values: Impact on Fertility Change. Oxford: Oxford University Press.

Montgomery, Mark R. and Jianping Zhao. 1998. "Social learning and networks in the diffusion of fertility control." Paper presented at the Annual Meeting of the Population Association of America, Chicago.

Moscovici, Serge. 1985. "Social influence and conformity." In G. Lindzey and E. Aronson (eds.), Handbook of Social Psychology, vol. II, New York: Random House.

Munshi, Kaivan. 1994. "Social learning and technology diffusion: An application to Indian agriculture." Unpublished paper, Department of Economics, MIT. 
Munshi, Kaivan and Jacques Myaux. 1998. "Social effects in the demographic transition: Evidence from Matlab, Bangladesh.” Unpublished paper, Department of Economics, Boston University.

National Academy of Sciences. 1993. "Local social organization and the diffusion of family planning." In Factors Affecting Contraceptive Use in subSaharan Africa. Washington D.C.: National Academy Press.

Nazzar, Alex et al. 1995. "Developing a culturally appropriate family planning program for the Navrongo experiment." Studies in Family Planning 26(6): 307-324.

Ngom, Pierre. 1995. "Resistance to family planning in Senegal: The role of women's informal conversations." Paper presented at the Annual Meeting of the Population Association of America.

Nowak, Andrzej, Jacek Szamrej, and Bibb Latane. 1990. "From private attitude to public opinion: A dynamic theory of social impact." Psychological Review 97(3): 363-376.

Palmore, James and Ronald Freedman. 1969. "Perceptions of contraceptive practice by others: Effects on acceptance.” In Ronald Freedman and J. Takeshita (eds.), Family Planning in Taiwan: An Experiment in Social Change. Princeton: Princeton University Press.

Phillips, James F. et al. 1997a. "Survey research on reproductive preferences and contraceptive use in traditional Africa: Are the responses meaningful?" Paper presented at the 125th Annual Meeting of the American Public Health Association, Indianapolis.

Phillips, James F. et al. 1997b. "The determinants of contraceptive innovation: A case-control study of family planning acceptance in a traditional African society." Policy Research Division Working Paper No. 93. New York: Population Council. 
Pollak, Robert. 1976. "Interdependent preferences." American Economic Review 66: 309-320.

Retherford, Robert. 1985. "A theory of marital fertility transition." Population Studies 39: 249-268.

Retherford, Robert and James Palmore. 1983. "Diffusion processes affecting fertility regulation." In Rodolfo A. Bulatao and Ronald D. Lee (eds.), Determinants of Fertility in Developing Countries, vol. 2. New York: Academic Press.

Richards, Toni. 1977. "Fertility decline in Germany: An econometric reappraisal." Population Studies 31(3): 537-553.

Rogers, Everett M. and D. Lawrence Kincaid. 1981. Communication Networks: Toward a New Paradigm for Research. New York: The Free Press.

Rosero-Bixby, Luis and John B. Casterline. 1993. "Modelling diffusion effects in fertility transition.” Population Studies 47(1): 147-167.

1994. "Interaction diffusion and fertility transition in Costa Rica." Social Forces 73(2):435-462.

Rust, John. 1994. "Structural estimation of Markov decision models." In Robert F. Engle and Daniel L. McFadden (eds.), Handbook of Econometrics, vol. 4, pp. 3082-3143. Amsterdam: Elsevier Science.

Shiller, R. 1995. "Conversation, information and herd behavior." American Economic Review 85(2): 181-185.

Strang, David. 1991. "Adding social structure to diffusion models.” Sociological Methods and Research 19(3): 324-353.

Tolnay, Stewart E. 1995. "The spatial diffusion of fertility: A cross-sectional analysis of countries in the American South, 1940." American Sociological Review 60: 299-308. 
Valente, Thomas W. 1995. Network Models of the Diffusion of Innovations. Cresskill, NJ: Hampton Press.

Valente, Thomas W. et al. 1997. "Social network associations with contraceptive use among Cameroonian women in voluntary associations." Social Science and Medicine 45(5): 677-687.

Watkins, Susan C. 1987. "The fertility transition: Europe and the Third World compared.” Sociological Forum 2(4): 645-673.

Watkins, Susan C. and Dennis Hodgson. 1998. "Global networks of the population movement." Paper presented to the National Academy of Sciences workshop, "The Social Dynamics of Fertility Change in Developing Countries," Washington, D. C.

Watkins, Susan C., Naomi Rutenberg, and Steven Green. 1995. "Diffusion and debate: Controversy about reproductive change in Nyanza Province, Kenya." Paper presented at the Annual Meeting of the Population Association of America.

Wolpin, Kenneth I. 1998. "The impact of infant and child mortality risk on fertility." In Mark R. Montgomery and Barney Cohen (eds.), From Death to Birth: Mortality Decline and Reproductive Change, pp. 74-111. Washington, D. C.: National Academy Press. 


\title{
POLICY RESEARCH DIVISION WORKING PAPERS
}

\author{
Recent Back Issues
}

1996

*83 Sajeda Amin, Ian Diamond, and Fiona Steele, "Contraception and religious practice in Bangladesh."

84 John B. Casterline, Aurora E. Perez, and Ann E. Biddlecom, "Factors underlying unmet need for family planning in the Philippines."

85 Geoffrey McNicoll, "Governance of fertility transition: Regularity and duress."

*86 John Bongaarts, "Population pressure and the food supply system in the developing world."

87 Sajeda Amin, "Family structure and change in rural Bangladesh."

*88 John Bongaarts and Susan Cotts Watkins, "Social interactions and contemporary fertility transitions."
*89 Cynthia B. Lloyd and Mark R. Montgomery, "The consequences of unintended fertility for investments in children: Conceptual and methodological issues."

*90 Zeba Sathar and Sonalde Desai, "Work patterns in rural Pakistan: Intersections between gender, family, and class."

*91 Mark R. Montgomery, "Learning and lags in mortality perceptions."

92 Ann E. Biddlecom, John B. Casterline, and Aurora E. Perez, "Men's and women's views of contraception."
93 James F. Phillips, Fred N. Binka, Martin Adjuik, Alex Nazzar, and Kubaze Frank Adazu, "The determinants of contraceptive innovation: A case-control study of family planning acceptance in a traditional African society."
94 John Bongaarts and Sajeda Amin, "Prospects for fertility decline and implications for population growth in South Asia."

95 Barbara S. Mensch and Cynthia B. Lloyd, "Gender differences in the

* No longer available 
schooling experiences of adolescents in low-income countries: The case of Kenya."

96 Martin Brockerhoff and Ellen Brennan, "The poverty of cities in the developing world."

*97 Carol E. Kaufman, "Reproductive control in South Africa."

98 John Bongaarts, "Trends in unwanted childbearing in the developing world."

99 Mary Arends-Kuenning, "How do family planning workers' visits affect women's contraceptive behavior in Bangladesh?"

100 Mark R. Montgomery and Cynthia B. Lloyd, "Excess fertility, unintended births, and children's schooling."
101 Mary Arends-Kuenning, "The equity and efficiency of doorstep delivery of contraceptives in Bangladesh."

*102 Sajeda Amin, Ian Diamond, Ruchira T. Naved, and Margaret Newby, "Transition to adulthood of female factory workers: Some evidence from Bangladesh."

*103 Margaret E. Greene and Ann E. Biddlecom, "Absent and problematic men: Demographic accounts of male reproductive roles."

104 Michael P. Todaro, "Urbanization, unemployment, and migration in Africa: Theory and policy."

105 Geoffrey McNicoll, "Population and poverty: A review and restatement."
106 Sajeda Amin and Gilda Sedgh, "Incentive schemes for school attendance in rural Bangladesh."

107 Martin Brockerhoff and Paul Hewett, "Ethnicity and child mortality in subSaharan Africa."

108 Ann E. Biddlecom and Bolaji M. Fapohunda, "Covert contraceptive use: Prevalence, motivations, and consequences."

109 John Bongaarts and Griffith Feeney, "On the quantum and tempo of fertility."
110 Barbara S. Mensch, Daniel Bagah, Wesley H. Clark, and Fred Binka, "The changing social environment for adolescents in the Kassena-Nankana District of northern Ghana: Implications for reproductive behavior."

111 Martin Brockerhoff and Ann Biddlecom, "Migration, sexual behavior, and HIV diffusion in Kenya."

112 Zeba A. Sathar and John B. Casterline, "The onset of fertility transition in $\mathrm{Pa}$ kistan."

* No longer available 
113 Geoffrey McNicoll, "Government and fertility in transitional and posttransitional societies."

114 John Bongaarts, "Fertility and reproductive preferences in post-transitional societies."

115 Fiona Steele, Sajeda Amin, and Ruchira T. Naved, "The impact of an integrated micro-credit program on women's empowerment and fertility behavior in rural Bangladesh."

116 Cynthia B. Lloyd, Barbara S. Mensch, and Wesley H. Clark, "The effects of primary school quality on the educational participation and attainment of Kenyan girls and boys."
117 Sajeda Amin and Cynthia B. Lloyd, "Women's lives and rapid fertility decline: Some lessons from Bangladesh and Egypt."

118 James F. Phillips and Mian Bazle Hossain, "The impact of family planning household service delivery on women's status in Bangladesh."

119 Mark R. Montgomery and John B. Casterline, "Social networks and the diffusion of fertility control." 